\title{
Sign Restrictions in Structural Vector Autoregressions: A Critical Review*
}

\author{
Renee Fry ${ }^{\dagger}$ and Adrian Pagan ${ }^{\ddagger}$
}

December 1, 2009

\section{Contents}

1 Introduction $\quad 2$

2 Summarizing the Data and Structural Representations $\mathbf{5}$

2.1 VAR and SVAR Representations ............ 5

2.2 Other Representations ................. 7

2.3 Two examples . . . . . . . . . . . . . . . . . . 8

2.3.1 A Market (Demand/Supply) Model . . . . . . . . 8

2.3.2 A Small Macro Model . . . . . . . . . . . 9

3 Methodology And Informativeness of SVAR Modelling Using Sign Restrictions $\quad 10$

3.1 Generating Candidate Shocks . . . . . . . . . . . . 10

3.1.1 Multiple Shocks . . . . . . . . . . . . . . . 10

3.1 .2 A Single Shock . . . . . . . . . . . . . . . 12

3.1.3 Permanent and Transitory Shocks . . . . . . . . . 13

3.1.4 Givens Matrices . . . . . . . . . . . . . . 13

3.1.5 Householder Transformations . . . . . . . . . . . . 15

3.2 Shock Identification Issues . . . . . . . . . . . . . . . 15

${ }^{*}$ We are greatful to referees for some very helpful suggestions regarding the structure of this review.

${ }^{\dagger}$ Australian National University

$\ddagger$ University of New South Wales and Queensland University of Technology 
3.2.1 The Parametric Approaches . . . . . . . . . . . . 15

3.2.2 Ensuring Structural Identification with Sign Restrictions 16

3.2 .3 Model Identification . . . . . . . . . . . . . . . 17

3.3 Information Provided by Sign Restrictions: Can We Recover Correct Impulse Responses? . . . . . . . . . . . . . . . . . 23

3.4 Sources of Information for Sign Restrictions . . . . . . . . . 24

4 Sign Restrictions in Practice 26

4.1 Technology and Productivity . . . . . . . . . . . . . 27

4.2 Fluctuations . . . . . . . . . . . . . . . . . . . . . . . . . . . 29

4.3 Monetary and Fiscal Policy _ . . . . . . . . . . . . . 32

4.4 Exchange Rates . . . . . . . . . . . . . . . . . . . . 36

4.5 Miscellaneous . . . . . . . . . . . . . . . . . . . 39

5 Conclusion 41

6 References 42

$\begin{array}{lll}7 & \text { Appendix } & 47\end{array}$

\section{Introduction}

Structural Vector Autoregressions (SVARs) have become one of the major ways of extracting information about the macro economy. One might cite three major uses of them in macro-econometric research.

1. For quantifying impulse responses to macroeconomic shocks.

2. For measuring the degree of uncertainty about the impulse responses or other quantities formed from them.

3. For deciding on the contribution of different shocks to business cycles and forecast errors through variance decompositions.

To determine this information a VAR is first fitted to summarize the data and then a structural VAR (SVAR) is proposed whose structural equation errors are taken to be the economic shocks. The parameters of these structural equations are then estimated by utilizing the information in the VAR. The VAR is a reduced form which summarizes the data; the SVAR provides an interpretation of the data. As for any set of structural equations, recovery of the structural equation parameters (shocks) requires the use of identification restrictions that reduce the number of "free" parameters in the structural 
equations to the number that can be recovered from the information in the reduced form.

Five major methods for recovering the structural equation parameters are listed below. The first four utilize parametric restrictions to produce enough instruments for the contemporaneous endogenous variables that appear in the structural equations.

(i) In the original approach to structural equation estimation the Cowles Commission regarded the structural shocks as being correlated and solved the identification problem by excluding variables from the structural equations. Often the excluded variables were lagged endogenous variables. One disadvantage of this solution is that any correlation between the shocks makes exercises involving the decomposition of the variance of a variable into the contribution from separate structural shocks infeasible.

(ii) Following Wold (1951) and Quenouille (1957), Sims (1980) proposed that the structural system be made recursive and that no restriction be placed upon the dynamics. Recursivity actually embodies two separate assumptions - that the shocks in the structural equations be uncorrelated with one another and that the endogenous variables can be arranged (ordered) so that each contemporaneously depends on others further down the system, but not on those above i.e. the system is made to exhibit a triangular structure. The triangularity might be justified by institutional knowledge, while the plausibility of the uncorrelated shocks depends on whether the SVAR adequately captures the macro-economic system. In turn this latter feature requires both a sufficient number of variables to be included in the VAR and a lag length of high enough order to adequately capture the dynamics.

(iii) Recognizing that some macro-economic variables are best thought of as being stochastically non-stationary brings in the fact that there may be shocks with permanent effects upon those variables. "Long-run restrictions" exploit this fact. Denoting the $j^{\prime}$ th horizon impulse responses of the variables to the shocks as $C_{j}$, the long-run effects of shocks will be $C_{\infty}$. A permanent effect of the $i^{\prime} t h$ shock upon the $k^{\prime} t h$ variable is then distinguished from a transitory shock by there being a non-zero element in the $k^{\prime}$ th row and $i^{\prime} t h$ column of $C_{\infty}$. These can be translated into linear restrictions upon the structural coefficients of an SVAR - see Shapiro and Watson (1988), Pagan and Robertson (1998). Such restrictions reduce the number of parameters to be estimated and free up instruments from among the lagged values of the variables.

(iv) Parametric impulse response restrictions are sometimes used to pro- 
vide identification. For example, if it is assumed that the $i$ th structural shock has no immediate effect upon a variable $y_{k t}$, this can be shown to mean that the errors in the VAR equation for $y_{k t}$ are not a function of the $i$ 'th structural shock - see Pagan and Robertson(1998). It follows then that the residuals from this equation can be used as an instrument in the structural equation for $y_{k t}$, provided the assumption that the structural shocks are uncorrelated is correct.

All of the methods described above impose parametric restrictions. Recently, a fifth method for estimating SVARs has arisen that employs sign restrictions upon the impulse responses as a way of identifying shocks. It also assumes that shocks are uncorrelated. Applications of this method have been growing as seen in the papers listed in Table 3. Consequently, it is worth examining this literature in more detail and the aim of our paper is to exposit how the method works, to identify some difficulties in its application, and to examine the empirical work gathered in Table 3.

In practical applications it is often found that a combination of all the methods mentioned above need to be employed in order to be able to identify all the shocks of interest. We emphasize that which of the five methods noted above is used in practice does not depend on the data, but rather on the preferences of the investigator and/or of those who wish to utilize an SVAR to study some issue. These preferences may well be incompatible as some users may feel that certain types of restrictions are more plausible than others. Prima facie it does seem likely that long-run and sign restrictions would be regarded as less restrictive than the other approaches, but without a specific context we have no basis for recommending any particular approach. Each has difficulties and these need to be understood to make an informed judgement on their utility. Although it is likely in practice that a mixed set of restrictions will be employed, because the literature on sign restrictions is more recent than that on the other methods it is convenient to simply assume that only sign restrictions are being employed.

Section 2 asks how the data should be summarized? The existing literature implicitly assumes that the answer is a VAR in some observable variables. But this may not be satisfactory in all contexts. First, when there are permanent shocks and co-integration between variables a VECM rather than a VAR will be needed. Second, if we wish to align the summary model with theoretical models it is often necessary to recognize that, whilst the latter generally implies a VAR in all the model variables, in practice only a sub-set often appear in the VAR that is estimated on actual data. This 
discrepancy may either be because some of the model variables are latent or because they are believed to be hard to measure accurately. When there is a divergence it becomes important to ask whether a VAR is the right vehicle to adopt as the summative model, and how one would proceed to apply sign restrictions if the context suggests that it is not. This section also introduces two simple models that are useful for understanding the issues raised in the application of sign restrictions - a two equation market model ( supply and demand) and a three equation macro model.

Section 3 begins by setting out the techniques that have been proposed to apply sign restrictions and briefly describes the main numerical methods used. It then looks at how each of the parametric and sign-restriction approaches works in the context of the market model. In all approaches, parametric or sign-restricted, the restrictions are designed to solve what will be called the structural identification problem. However they leave unresolved what Preston (1978) called the model identification problem. The problem seems to have elicited much more attention in the sign restrictions literature and so we look at the various suggestions that have been made about how to handle it. Finally, we close the section by looking at what can be learned from the use of sign restrictions and where the restrictions might come from. To answer the latter we utilize the New Keynesian model as a prototype for how some suggestions have been made about isolating suitable sign information. Section 4 surveys some existing empirical applications and provides an account of how they have proceeded, where the sign information came from, and what difficulties arise in the way the authors have proceeded. It is our contention that one needs a template for examining such studies and we seek to provide that. Section 5 concludes.

\section{Summarizing the Data and Structural Rep- resentations}

\subsection{VAR and SVAR Representations}

Most of the literature we deal with assumes that the data is represented by a VAR ( for simplicity we will make it first order)

$$
z_{t}=A_{1} z_{t-1}+e_{t}
$$


where $z_{t}$ is an $n \times 1$ vector of variables. From this an interpretation of the data is provided through a SVAR

$$
B_{0} z_{t}=B_{1} z_{t-1}+\varepsilon_{t}
$$

which implies that $B_{0} e_{t}=\varepsilon_{t}$ i.e. the structural shocks we seek to measure are linear combinations of the VAR errors $e_{t}$. The latter can be estimated by the VAR residuals $\hat{e}_{t}$. To estimate the structural (economic) shocks, $\varepsilon_{t}$, then requires that one construct an appropriate set of weights $\left(\hat{B}_{0}\right)$ on $\hat{e}_{t}$. Clearly the VAR is the reduced form of the structure set out in the SVAR.

The solution to the $\operatorname{VAR}(1)$ is the MA form

$$
z_{t}=D_{0} e_{t}+D_{1} e_{t-1}+D_{2} e_{t-2}+\ldots
$$

where $D_{j}$ is the $\mathrm{j}$ 'th period impulse response of $z_{t+j}$ to a unit change in $e_{t}$ $\left(D_{0}=I_{n}\right)$. It follows that the MA form for the SVAR is

$$
z_{t}=C_{0} \varepsilon_{t}+C_{1} \varepsilon_{t-1} \ldots
$$

with the impulse responses to $\varepsilon_{t}$ being $C_{j}=D_{j} B_{0}^{-1}=D_{j} C_{0}$.

The VAR is easily estimated by OLS regardless of the nature of the SVAR. Hence $D_{j}$ can always be estimated once the lag length of the VAR is specified. Because $\hat{C}_{j}=\hat{D}_{j} \hat{C}_{0}$, and $\hat{D}_{j}$ is fixed by the data independently of any structural model, all restrictions that are placed on $C_{j}$ are effectively just restrictions upon combinations of the columns of $C_{0}$, with the weights used in forming such combinations being the rows of $D_{j}$. To understand many issues regarding sign restrictions it is important to realize that we are always restricting the elements of $C_{0}$. Such restrictions might be imposed on $C_{0}$ directly but they also derive from restrictions on impulses at longer horizons e.g. information about the signs of the elements of $C_{1}$ imply constraints upon combinations of the elements of $C_{0}$. If the restrictions on $C_{1}$ are quantitative this fact narrows the possible values of $C_{0}$. However, the same effect does not necessarily hold for sign restrictions. For example, if all elements of $C_{0}$ are positive, and so too are the estimated $D_{1}$ from the data, then a restriction that the elements of $C_{1}$ are positive adds nothing to what has already been assumed about the signs of $C_{0}$. There is a belief in the literature that adding on sign restrictions for longer impulse responses, $C_{j}, j>0$, provides stronger identifying information. This seems to stem from the Monte Carlo work in Paustian (2007). It is clear from the connections that exist between the $C_{j}$ and $C_{0}$ noted above that nothing guarantees this. 


\subsection{Other Representations}

Now if we try to align theory-inspired interpretative models ( such as DSGE models) with the summative model we often encounter the situation that there are variables in the former that are not observable and so the latter model is fitted with a smaller number of variables. ${ }^{1}$ Let the observable variables (data) be $z_{t}$ and the larger set in the theoretical model be $z_{t}^{+}$. Then, it has been known for a long time, see Wallis(1977) and Zellner and Palm (1974), that a VAR in $z_{t}^{+}$becomes a VARMA in $z_{t}$. Thus a VAR will not represent the data precisely if it should be generated by a theoretical model with latent (unobserved) variables, although if one makes the order sufficiently high it might be argued to be approximately correct. Basically this implies that the impulse responses from the theoretical model, $C_{j}^{+}$, will not be equal to those from an approximating VAR, unless the order is infinite. As shown in Kapetanios et al (2006), this difference can be very large for some shocks and models and so one needs to exercise care in using information from theory-consistent models to identify shocks in VARs. ${ }^{2}$ Of course it is possible that this problem is less of an issue for the signs of the responses than it is for the magnitudes i.e. the signs of $C_{j}^{+}$and $C_{j}$ may agree even if the magnitudes don't. Fundamentally the problem is that a VAR is not the correct summative model. ${ }^{3}$ As an alternative one might estimate a VARMA process or a VAR with some latent variables but it is probably simpler to focus on the state space form

$$
\begin{aligned}
z_{t} & =H z_{t}^{+} \\
z_{t}^{+} & =M z_{t-1}^{+}+e_{t}^{+}
\end{aligned}
$$

and estimate this. Readily available computer programs such as Dynare are designed to do so. Thus the role of a theory-inspired model is to provide the variables in $z_{t}^{+}$and the order of the VAR associated with them, while the empirical investigator selects $z_{t}$. Because sign restrictions often come from DSGE models we return to the issue later.

\footnotetext{
${ }^{1}$ Technology is an obvious example of a variable in a DSGE model that is rarely present in an estimated VAR. But it is also the case that researchers often treat the capital stock as unobservable and so it is omitted from the list of variables in the empirical VAR.

${ }^{2}$ Using a model that was a smaller version of BEQM and a VAR with a standard set of six variables it was found that a $\operatorname{VAR}(50)$ and thirty thousand observations were needed to recover the true impulse responses.

${ }^{3}$ There are even cases where there is no invertible MA representation, and so no VAR exists.
} 
If there are permanent shocks with no co-integration between variables then the VAR and SVAR will simply involve differences in the variables $z_{t}$ rather than the levels, so it is just how the data is measured that changes. Sometimes one sees the summative model in the sign restrictions literature as a DVAR i.e. a VAR in the differences $\Delta z_{t}$. Examples are Jarociński and Smets (2008) and Farrant and Peersman (2006). Often it does not seem to be appreciated that in this case all shocks are permanent ( assuming that the only variables in $z_{t}$ are $I(1)$ ). When there is co-integration the summative model will be the Vector Error Correction Model (VECM)

$$
\Delta z_{t}^{+}=\alpha \beta^{\prime} z_{t-1}^{+}+e_{t},
$$

and a Structural VECM (SVECM) will interpret this data

$$
B_{0} \Delta z_{t}^{+}=\left(B_{0} \alpha\right) \beta^{\prime} z_{t-1}^{+}+\varepsilon_{t} .
$$

Thus, as these are relatively simple extensions of the standard approach, one does not need any special development. It should be emphasized that the VECM would be in $z_{t}^{+}$rather than (observed) $z_{t}$, as the level of the log of technology will generally be a latent variable appearing in $z_{t}^{+}$but not in $z_{t}$. Thus the problems identified above relating to latent variables occur again although they can be solved in the same way viz. via the state space form.

\subsection{Two examples}

\subsubsection{A Market (Demand/Supply) Model}

We take the case of a simple model comprising a demand and a supply function with associated shocks. Specifically the SVAR system will be

$$
\begin{aligned}
& q_{t}=-\beta p_{t}+\phi_{q q} q_{t-1}+\phi_{q p} p_{t-1}+\varepsilon_{D t} \\
& p_{t}=\gamma q_{t}+\phi_{p q} q_{t-1}+\phi_{p p} p_{t-1}+\varepsilon_{S t},
\end{aligned}
$$

Hence in terms of the SVAR discussion above $z_{t}=\left[\begin{array}{c}q_{t} \\ p_{t}\end{array}\right]$. The reduced form of the market model is a $\operatorname{VAR}(1)$. Since the equations (2) and (3) are essentially identical for arbitrary parameter values, at this point there is nothing which distinguishes the demand $\left(\varepsilon_{D t}\right)$ and supply shocks $\left(\varepsilon_{S t}\right)$, and the task is to introduce extra information that does enable us to identify these. It 
would seem likely that most researchers would agree with the sign information in Table 1 for the impact of positive shocks upon the contemporaneous variables. Since the patterns are distinct this suggests that we can identify separate shocks.

There is one complication. Because a negative movement in each shock would produce a pattern in $C_{0}$ of $\left[\begin{array}{cc}- & + \\ - & -\end{array}\right]$ it is necessary to recognize that such a sign pattern is also consistent with demand and supply shocks, albeit negative ones. This is clearly not the end of the matter, since $\left[\begin{array}{ll}- & - \\ - & +\end{array}\right]$ and $\left[\begin{array}{cc}+ & + \\ + & -\end{array}\right]$ are also indicative of demand and supply shocks, but now of opposite signs. So one needs to allow for all of these possibilities in deciding if a given pattern in impulse responses is consistent with a demand and supply shock. Clearly the need to check for the complete set of compatible sign restrictions will grow as the number of shocks increases.

\begin{tabular}{|l|l|l|}
\hline \multicolumn{2}{|c|}{ Table 1: Sign Restrictions for Market } \\
\hline \multicolumn{2}{|c|}{ Model (Demand/Supply) Shocks } \\
\hline & & \\
\hline variable $\backslash$ shock & Demand & Supply \\
\hline$p_{t}$ & + & - \\
\hline$q_{t}$ & + & + \\
\hline
\end{tabular}

\subsubsection{A Small Macro Model}

A small macro model that is used a lot involves an output gap $\left(y_{t}\right)$, inflation $\left(\pi_{t}\right)$ and a policy interest rate $\left(i_{t}\right)$. i.e. $z_{t}^{\prime}=\left[\begin{array}{lll}y_{t} & \pi_{t} & i_{t}\end{array}\right]$. A typical SVAR model for these variables would be

$$
\begin{aligned}
y_{t} & =z_{t-1}^{\prime} \gamma_{y}+\alpha_{y i} i_{t}+\alpha_{y \pi} \pi_{t}+\varepsilon_{y t} \\
\pi_{t} & =z_{t-1}^{\prime} \gamma_{\pi}+\alpha_{\pi i} i_{t}+\alpha_{\pi y} y_{t}+\varepsilon_{\pi t} \\
i_{t} & =z_{t-1}^{\prime} \gamma_{i}+\alpha_{i y} y_{t}+\alpha_{i \pi} \pi_{t}+\varepsilon_{i t}
\end{aligned}
$$

The three shocks will be monetary policy $\left(\varepsilon_{i t}\right)$, a demand shock $\left(\varepsilon_{y t}\right)$ and a cost-push ( supply) shock $\left(\varepsilon_{\pi t}\right)$. For simplicity the shocks will be treated as having no serial correlation, so that the reduced form is a $\operatorname{VAR}(1)$. The signs of the contemporaneous effects to positive shocks will most likely be those 
in Table 2. Again these are distinct and so should enable the separation of the three structural shocks. Again we would need to recognize the problem with different signs, as there will now be nine possible signs for the $C_{0}$ that are compatible with the presence of the three postulated shocks.

\begin{tabular}{|l|l|l|l|}
\hline \multicolumn{4}{|c|}{ Table 2: Sign Restrictions for Macro Model Shocks } \\
\hline & & & \\
\hline variable\shock & Demand & Cost-Push & Interest Rate \\
\hline$y_{t}$ & + & - & - \\
\hline$\pi_{t}$ & + & + & - \\
\hline$i_{t}$ & + & + & + \\
\hline
\end{tabular}

\section{Methodology And Informativeness of SVAR Modelling Using Sign Restrictions}

\subsection{Generating Candidate Shocks}

\subsubsection{Multiple Shocks}

In all cases a set of $n$ estimated shocks $\hat{e}_{t}$ will be available from the model we choose to be the summative one. By combining them in an appropriate way we can produce candidate structural shocks $\hat{\varepsilon}_{t}$ that are uncorrelated. Now there will be many such combinations. Some of them will produce impulse responses that have the correct signs while others won't. Thus in the market model case there will only be some weights which produce shocks that respect the patterns in Table 1. So our first task is to select an algorithm that gives a set of weights. Once one has these we can check if they are "successful", in that the impulse response functions $\hat{C}_{j}$ for the corresponding structural shocks agree with the postulated sign information. If they are not successful we will discard them and "draw" another set of weights.

Now the critical constraint needed in designing an algorithm to do this is that the generated weights must be such as to ensure that the constructed structural shocks $\hat{\varepsilon}_{t}$ are uncorrelated. Suppose we begin by first estimating a recursive VAR. In that case after estimation we would have $\hat{e}_{t}=\hat{B}_{0}^{-1} \hat{\varepsilon}_{t}$, where $\hat{B}_{0}$ is triangular. By design these structural shocks, $\hat{\varepsilon}_{t}$, are uncorrelated. However, rather than work with these it is often more useful to work with shocks that have unit variance, and this can be done by dividing each of the $\hat{\varepsilon}_{k t}$ by its standard deviation. Hence, let $\hat{S}$ be the matrix that has the 
estimated standard deviations of the $\hat{\varepsilon}_{t}$ on the diagonal and zeros elsewhere. Then $\hat{e}_{t}=\hat{B}_{0}^{-1} \hat{S} \hat{S}^{-1} \hat{\varepsilon}_{t}=\hat{T} \hat{\eta}_{t}$, where $\hat{\eta}_{t}=\hat{S}^{-1} \hat{\varepsilon}_{t}$ are now new structural shocks that do possess unit variances. These $\hat{\eta}_{t}$ shocks will be termed our base set. Notice that they are just a re-scaled version of the $\hat{\varepsilon}_{t}$, so their nature has not changed. ${ }^{4}$

Now we form combinations of the $\hat{\eta}_{t}$ using a matrix $Q$ i.e. $\hat{\eta}_{t}^{*}=Q \hat{\eta}_{t}$. The $\hat{\eta}_{t}^{*}$ are candidates for "named" structural shocks e.g. "supply" and "demand". They need to be uncorrelated and so $Q$ must be restricted. The appropriate restriction is that $Q$ is a square matrix such that $Q^{\prime} Q=Q Q^{\prime}=I_{n}$, since that means

$$
\begin{aligned}
\hat{e}_{t} & =\hat{T} Q^{\prime} Q \hat{\eta}_{t} \\
& =\hat{T}^{*} \hat{\eta}_{t}^{*},
\end{aligned}
$$

and $\operatorname{cov}\left(\eta_{t}^{*} \eta_{t}^{* \prime}\right)=Q \operatorname{cov}\left(\hat{\eta}_{t} \hat{\eta}_{t}^{\prime}\right) Q^{\prime}=I_{n}$. Thus we have found a new set of shocks, $\hat{\eta}_{t}^{*}$, that have the same covariance matrix as $\hat{\eta}_{t}$ (and which will reproduce the $\left.\operatorname{var}\left(z_{t}\right)\right)$, but which will have a different impact $\left(\hat{T}^{*}\right)$ upon $e_{t}$ and, hence, the variables $z_{t}$ i.e. produce different impulse responses. It is this ability to create a large number of candidate shocks with varying impulse responses that is the basis of sign restriction methods. It is clearly very simple to construct all these shocks using programs that do matrix operations once we have a method for forming a $Q$ that has the property $Q^{\prime} Q=Q Q^{\prime}=I_{n}$. There are many such $Q^{\prime} s$ and we will refer to each as a "draw".

How does one find a $Q$ matrix? There are actually quite a few ways of doing this. The two most popular utilize Givens and Householder transformations (the latter is the basis of the Q-R decomposition used in many ill-conditioned regression problems), but this does not exhaust the possibilities. We provide an account of each of these and the relationship between them in later sub-sections.

\footnotetext{
${ }^{4}$ Numerically it is generally more efficient to estimate $\hat{\eta}_{t}$ by estimating the covariance matrix of the residuals $\hat{e}_{t}, \hat{\Omega}$, and then applying a Cholesky decomposition $\hat{T}^{-1} \hat{\Omega} \hat{T}^{\prime-1}=I_{n}$ to get $\hat{T}$. Then $\hat{\eta}_{t}=\hat{T}^{-1} \hat{e}_{t}$. This is a useful way of proceeding since all that is needed to implement it is the estimated covariance matrix of the errors in the equations of the summative model. It also means that the summative model need not be a VAR. It could be a VECM or a state space model.
} 


\subsubsection{A Single Shock}

In the description above it was assumed that $n$ shocks were to be found. But sometimes only a single shock is of interest. To find this we might still utilize the $n \times n Q$-matrices above. In doing so we would be producing $n$ uncorrelated structural shocks, but only choosing to focus upon one of them. Two issues arise here. Firstly, in some papers one has the impression that it is only necessary that the weights used for constructing the structural shocks be an $n \times 1$ vector $q$ that has unit length. Uhlig's papers often state it in this way e.g Scholl and Uhlig (2008, p 5). If $q$ is not selected from $Q$ then the resulting shock need not be uncorrelated with the remaining (unidentified) $n-1$ shocks. To the extent that one does not need this property then there is no problem, but if one is trying to perform a variance decomposition it is mandatory. Our reading of a number of papers in the literature is that $q$ was not selected in a way to ensure orthogonality.

A second problem arises from the following scenario. Suppose that there are two variables and we believe that one shock has a positive initial effect on the first variable but are not willing to either describe its effects on the second variable or any of the signs of the initial effects of the second shock. This scenario would generate signs for $C_{0}$ of $\left[\begin{array}{cc}+ & ? \\ ? & ?\end{array}\right]$, where ? means that no sign information is provided. It is clear that this is not enough information to discriminate between the shocks. Indeed, even the pattern $\left[\begin{array}{cc}+ & ? \\ + & ?\end{array}\right]$ would not suffice, since it is possible that the impulse responses found from a draw of $Q$ might be $\left[\begin{array}{ll}+ & + \\ + & +\end{array}\right]$, and then we are faced with the fact that both shocks have the same sign pattern. In any finite number of draws one may not encounter this but that is just fortuitous. Hence a problem arises if there is a failure to specify enough information to discriminate between shocks. We will refer to this as the multiple shocks problem as distinct from the multiple models problem that will be dealt with later.

If in any draw there are two shocks with the same pattern for impulse responses what do we conclude about them? We can't count both of them, as the shocks are in the same model e.g. you can't have two demand shocks in the market model. We will see later that this situation occurs in one of the reported draws done in connection with the macro model above, when only one shock ( demand ) is being identified. Consequently if only a single shock 
is to be isolated ( more generally any number less than $n$ ) some information will need to be provided on what strategy was used to deal with this issue. At the moment little mention is made in some published articles using sign restrictions.

\subsubsection{Permanent and Transitory Shocks}

Some care needs to be exercised if there are both permanent and transitory shocks in the system. The VECM system has residuals $\hat{e}_{t}$ which can be converted to $n-r$ permanent $\hat{e}_{t}^{P}$ and $r$ transitory $\hat{e}_{t}^{T}$ shocks, where $r$ is the degree of co-integration. It is then necessary to re-combine these such that any new permanent and transitory shocks are formed by weighting the $\hat{e}_{t}^{P}$ and $\hat{e}_{t}^{T}$ respectively and are also uncorrelated. Since there must be $n-r$ permanent shocks in any SVAR, the simplest way to produce shocks with the requisite properties is to begin with a recursive SVAR in which $n-r$ of these are designated as permanent. The methodology outlined in Pagan and Pesaran (2008) illustrates this methodology.

\subsubsection{Givens Matrices}

In the context of a 3 variable VAR ( the macro model) a $3 \times 3$ Givens matrix $Q_{12}$ has the form

$$
Q_{12}=\left[\begin{array}{ccc}
\cos \theta & -\sin \theta & 0 \\
\sin \theta & \cos \theta & 0 \\
0 & 0 & 1
\end{array}\right]
$$

i.e. the matrix is the identity matrix in which the block consisting of the first and second columns and rows has been replaced by cosine and sine terms and $\theta$ lies between 0 and $\pi / 2$. $Q_{12}$ is called a Givens rotation. Then $Q_{23}^{\prime} Q_{23}=I_{3}$ using the fact that $\cos ^{2} \theta+\sin ^{2} \theta=1$. There are then three possible Given rotations for a three variable system; the other two are $Q_{13}$ and $Q_{23}$. Each of the $Q_{i j}$ depends on a separate parameter $\theta_{k}$. In practice most users of the approach have adopted the multiple of the basic set of Givens matrices as $Q$ e.g. in the three variable case we would use

$$
Q_{G}(\theta)=Q_{12}\left(\theta_{1}\right) \times Q_{13}\left(\theta_{2}\right) \times Q_{23}\left(\theta_{3}\right)
$$

It's clear that $Q_{G}$ is orthogonal and so shocks formed as $\eta_{t}^{*}=Q_{G} \eta_{t}$ will be uncorrelated and their impact upon $z_{t}$ will be $\hat{T}^{*}=\hat{T} Q_{G}^{\prime}$. 
Now, the matrix $Q_{G}$ above depends upon three different $\theta_{k}$. Canova and de Nicolo (2002) suggested that one make a grid of $M$ values for each of the values of $\theta_{k}$ between 0 and $\pi$, and then compute all the possible $Q_{G}$. Of course all of these models distinguished by different numerical values for $\theta_{k}$ are observationally equivalent in that they produce an exact fit to the variance of the data on $z_{t}^{5}$. Only those $Q_{G}$ producing shocks that agree with the maintained sign restrictions are then retained.

As an example we look at the macro model with some data described in Cho and Moreno (2006) on the US output gap, inflation and the Federal Funds rate. As described above begin with a recursive model i.e. impose $\alpha_{y i}=0, \alpha_{y \pi}=0, \alpha_{\pi i}=0$. OLS on each of (4)-(6) gives structural equation residuals that are uncorrelated. More potential structural shocks can then be found by combining these residuals with $Q$ matrices. Two of these $Q$ matrices from the Givens approach are given below. They have the property that $Q^{\prime} Q=I_{3}{ }^{6}$

$$
Q^{(1)}=\left[\begin{array}{ccc}
-.4551 & .3848 & .8030 \\
-.5853 & -.8089 & .0559 \\
.6710 & -.4446 & .5933
\end{array}\right], Q^{(2)}=\left[\begin{array}{ccc}
.0444 & -.8431 & .5359 \\
.8612 & -.2395 & -.4482 \\
.5062 & .4815 & .7155
\end{array}\right]
$$

When $Q^{(2)}$ is used the generated structural shocks have a sign pattern for $C_{0}$ of $\left[\begin{array}{ll}+ & - \\ + & + \\ + & + \\ + & +\end{array}\right]$, which disagrees with the restrictions in Table 2. In contrast, $Q^{(1)}$ does produce a set of impulse responses that is consistent with the table. Hence, employing the sign restriction methodology only the impulses found using $Q^{(1)}$ would be retained.

Weighting with the matrix $Q^{(2)}$ can also be used to illustrate the multiple shocks problem. Suppose we were only identifying a single shock - demand - using the sign restrictions from the macro model. Then, when we use $Q^{(2)}$ and construct three shocks, there would be two that produce the right signs to be called demand shocks. We cannot accept both as these as demand shocks given they are in the same model. It is only if one describes the signs patterns for all of the shocks that we can rule out the use of $Q^{(2)}$.

\footnotetext{
${ }^{5}$ It is assumed in the analysis that the $z_{t}$ have been mean corrected before the VAR is fitted.

${ }^{6}$ The fact that we retain only four decimal places above means that $Q^{\prime} Q$ is not exactly $I_{3}$.
} 


\subsubsection{Householder Transformations}

The alternative method of forming an orthogonal matrix $Q$ is to generate some random variables $W$ from an $N\left(0, I_{3}\right)$ density (for a three variable VAR) and then decompose $W=Q_{R} R$, where $Q_{R}$ is an orthogonal matrix and $R$ is a triangular matrix. Householder transformations of a matrix are used to decompose $W$. The algorithm producing $Q_{R}$ is often called a $\mathrm{QR}$ decomposition. Clearly $Q_{R}=I$ corresponds to the matrix used in recursive orderings. Since many draws of $W$ can be made, one can find many $Q_{R}$. Rubio-Ramirez (2005) et al. seem to have been the first to propose this, and they have argued that, as the size of the VAR grows, this is a computationally efficient strategy relative to the Givens approach. In Fry and Pagan (2007) we show that the methods are equivalent so the main factor in choice would be computational speed. As the system grows in side we would expect the Householder method to be superior.

\subsection{Shock Identification Issues}

\subsubsection{The Parametric Approaches}

In order to contrast the sign restriction approach to other methods of identifying shocks let us think about how one might estimate the market model using the parametric restrictions of the introduction (we ignore the first possibility of constraining some coefficients of lagged values to zero). These are designed to identify the structural equations and hence the shocks.

(i) If the system is assumed to be recursive e.g. $\beta$ is set to zero, then OLS can be applied to the supply equation since $q_{t}$ is a function of $\varepsilon_{D t}$ and this is uncorrelated with $\varepsilon_{S t}$. Three unknown parameters are left and there are three pieces of information - the estimated variances of $p_{t}, q_{t}$ and the covariance of $p_{t}$ and $q_{t}$.

(ii) A restriction that (say) a demand shock has no long-run effect upon the price would imply that $\gamma=-\phi_{p q}$ and so the supply curve would become a function of $\Delta q_{t}$ and $p_{t-1}$. This implies that there is one less structural parameter to estimate in the supply curve and $q_{t-1}$ has been freed up to be used as an instrument for $\Delta q_{t}$. Once the supply equation is estimated the demand equation can be found by using the residuals $\hat{\varepsilon}_{S t}$ as an instrument for $p_{t}$.

(iii) An assumption that the short run effect of a demand shock upon prices is zero would imply that the reduced form (VAR) equation for $p_{t}$ 
would be

$$
p_{t}=\psi_{1} q_{t-1}+\psi_{2} p_{t-1}+\frac{\gamma \varepsilon_{D t}}{(1-\beta \gamma)}+\frac{\varepsilon_{S t}}{(1-\beta \gamma)},
$$

where $\psi_{j}$ are functions of $\phi_{i j}$ and $\gamma, \beta$ must have $\frac{\gamma}{(1+\beta \gamma)}=0$, meaning that the VAR residual for $p_{t}$ would not involve $\varepsilon_{D t}$ and so can be used as an instrument for $p_{t}$ in the demand curve.

Thus in all cases the identification problem is solved by reducing the number of parameters to be estimated to three and in doing so suitable instruments are made available for estimation.

\subsubsection{Ensuring Structural Identification with Sign Restrictions}

So how do sign restrictions resolve the structural identification problem in the market model? For convenience we will suppress the dynamics as only restrictions on the contemporaneous impulses are being used. That information is in Table 1. For this discussion it is convenient to find some initial uncorrelated shocks by assuming that the system is recursive. Recursivity means that the moment conditions to get the base estimates of the structural parameters would be $E\left(q_{t} \varepsilon_{S t}\right)=0$ and $E\left(\varepsilon_{S t} \varepsilon_{D t}\right)=0$. Of course these assumptions may be incorrect but it is simply a mathematical device to generate a base set of shocks that can be re-combined and is not meant to imply that the system really is recursive. In this recursive scenario the base system is assumed to have the form

$$
\begin{aligned}
p_{t} & =\eta_{1 t} \\
q_{t}-\tau p_{t} & =\eta_{2 t}
\end{aligned}
$$

and $\eta_{1 t}, \eta_{2 t}$ are the base set of impulses.

Now keeping the uncorrelated shocks assumption we construct new shocks $\eta_{j t}^{*}$ using the base ones, $\eta_{1 t}=p_{t}$ and $\eta_{2 t}=q_{t}-\tau p_{t}$. The new uncorrelated shocks $\eta_{1 t}^{*}$ and $\eta_{2 t}^{*}$ will be constructed using a Givens rotation as the weighting matrix. Since there is only one Givens matrix in this case, $Q=\left[\begin{array}{cc}\cos \theta & -\sin \theta \\ \sin \theta & \cos \theta\end{array}\right]$, the transformed system becomes

$$
\left[\begin{array}{c}
\sigma_{\eta_{1}} \eta_{1 t}^{*} \\
\sigma_{\eta_{2}} \eta_{2 t}^{*}
\end{array}\right]=\left[\begin{array}{l}
p_{t} \cos \theta-\left(q_{t}-\tau p_{t}\right) \sin \theta \\
p_{t} \sin \theta+\left(q_{t}-\tau p_{t}\right) \cos \theta
\end{array}\right],
$$

where $\sigma_{\eta_{j}}$ is the standard deviation of $\eta_{j t}$, and reflects the fact that $\eta_{j t}^{*}$ was made to have a unit variance. Letting $\phi_{1}=\cos \theta$ and $\phi_{2}=\sin \theta$ the two 
equations can be written as

$$
\begin{aligned}
\left(\phi_{1}+\phi_{2} \tau\right) p_{t}-\phi_{2} q_{t} & =\sigma_{\eta_{1}} \eta_{1 t}^{*} \\
\left(\phi_{2}-\tau \phi_{1}\right) p_{t}+\phi_{1} q_{t} & =\sigma_{\eta_{2}} \eta_{2 t}^{*}
\end{aligned}
$$

with impulse responses of $\left(p_{t}, q_{t}\right)$ to $\sigma_{\eta_{j}} \eta_{j t}^{*}$ being

$$
\left[\begin{array}{cc}
\phi_{1}+\tau \phi_{2} & -\phi_{2} \\
\phi_{2}-\phi_{1} \tau & \phi_{1}
\end{array}\right]^{-1}=\frac{1}{\phi_{1}^{2}+\phi_{2}^{2}}\left[\begin{array}{cc}
\phi_{1} & \phi_{2} \\
-\phi_{2}+\tau \phi_{1} & \phi_{1}+\tau \phi_{2}
\end{array}\right] .
$$

So the sign of the impact of the shocks upon $p_{t}$ and $q_{t}$ will be dependent on $\operatorname{sgn}\left(\phi_{1}\right)$ and $\operatorname{sgn}\left(\phi_{2}\right)$ and these can be positive or negative depending upon the values taken by $\theta$. Consequently there will be many impulse responses which satisfy the sign restrictions and these are indexed by values of $\theta$. Note that, even though we started with a recursive system, we will generally not have one as $\theta$ varies.

It is useful now to observe that, given $\theta$, the number of unknown parameters in (7)-(8) has been reduced to three $\left(\tau, \sigma_{\eta_{1}}, \sigma_{\eta_{2}}\right)$, just as happened with the parametric methods. The essence of sign restrictions then is to impose a restriction upon the demand and supply curves that enables one to estimate the two elasticities. Put this way it is apparent that sign restrictions do impose parametric restrictions but these are functional, and are analogous to linear restrictions between parameters that come if one uses a real interest rate in an equation rather than a nominal one. The reduction in the number of unknown parameters to three in the example means that a unique set of parameters can be recovered for a given set of equations (and a specified $\theta$ ), and so the structural parameter identification problem has been solved.

\subsubsection{Model Identification}

Now in the discussion above we only retain those shocks whose impulses agreed with the postulated signs. But it is clear that there may be many impulse responses that satisfy these sign restrictions i.e. in terms of the Givens matrix it is unlikely that there will be a single value of $\theta$ that will produce the requisite sign restrictions. Figure 1 shows the large range of impulse responses one gets by applying the contemporaneous sign restrictions of Table 2 to the data that we used earlier when illustrating the effects of choosing two values for $Q$. It is noticeable that, even though the initial response of output to the interest rate has been forced to be negative, there 
s:demand r:gap

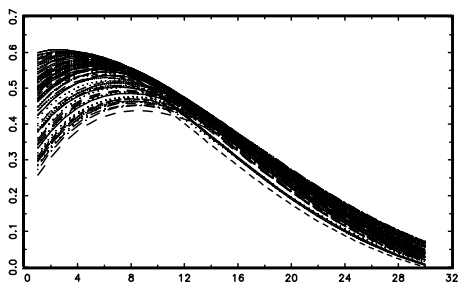

s:cost push r:gap

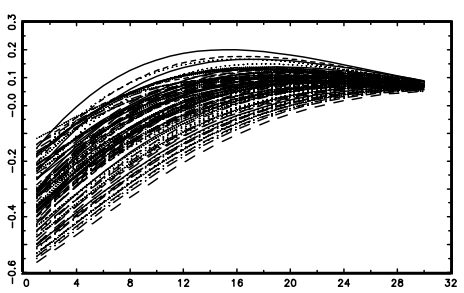

sint rate $r$ gap

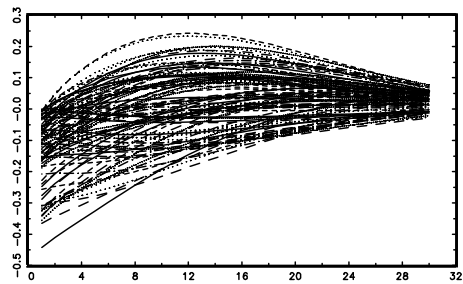

s:demand $r$ inf

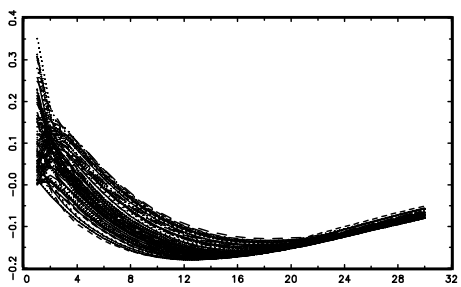

s:cost push $r$ inf

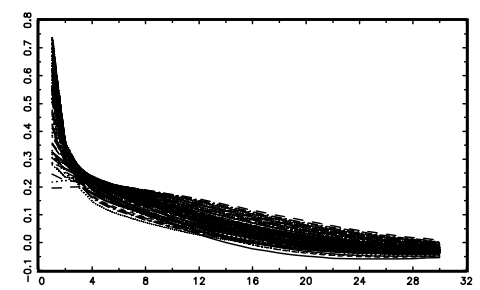

sint rate $r$ inf

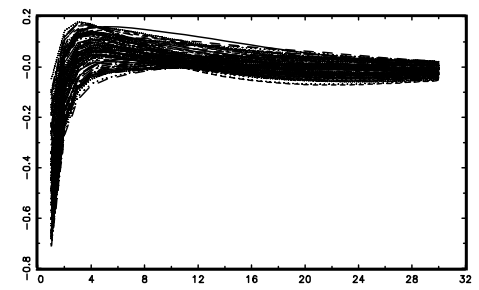

s:demand $r$ int

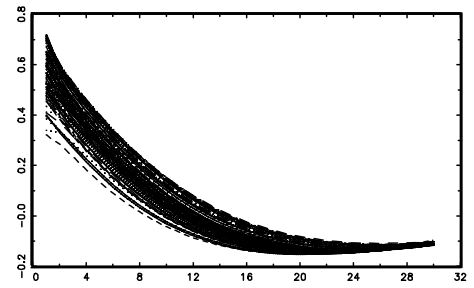

s:cost push rint

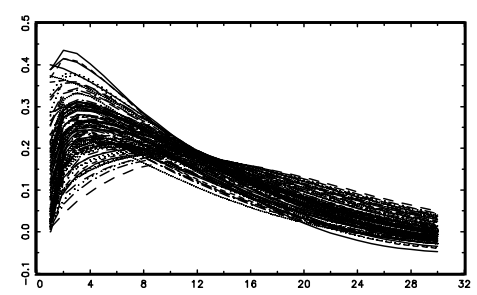

s:int rate $r$ int

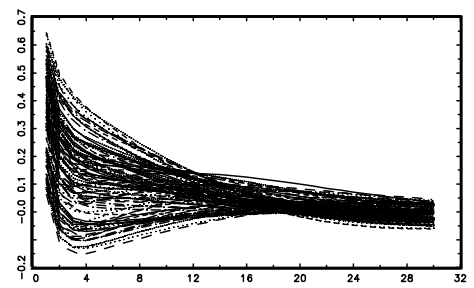

Figure 1: Impulse Responses for 1000 Macro Models Consistent with U.S. Data

are some cases where that response becomes positive very quickly. Each value of $\theta$ produces a new model i.e. a new set of structural equations and shocks. Consequently, although we have converted any given system of equations ( coming from a given $\theta$ ) to one that has a structure that is identified, we have not identified a unique model. The difference between structural and model identification was emphasized by Preston (1978).

Now it needs to be said that the issue of model identification is always present and is not specific to sign restrictions. Thus, if one used a recursive system to get structural identification, there are many other such systems (orderings) that will yield the same VAR i.e. give the same fit to the data. 
Each structure coming from a given ordering is identified but, as all of the orderings exactly replicate the data, there is no unique model unless one is prepared to consider that there is only one recursive model that is tenable as the data generating process, and that is rare e.g. Killian and Murphy (2009) work with recursive systems involving oil prices but resile from being dogmatic about any one recursive system, and one often sees comments to the effect that re-ordering the equations did not modify the conclusions much.

Why then should we pay any more attention to model identification for sign restrictions than for other ways of identifying VARs? Some insight into this comes from examining the two possible recursive versions of the market model. Although observationally equivalent the two models can be treated as different views about how the market operates. In one case quantity is treated as predetermined, and so prices reconcile supply and demand, while the other has price being set and quantity doing the adjustment. A choice between these might be made using institutional knowledge that is difficult to put into a VAR framework. But in the sign restriction approach to the market model there is no equivalent interpretation, as it just ties together the supply and demand elasticities. Nevertheless any solution to the multiple models problem has to be the same as for recursive models, namely the introduction of extra information that enables one to discriminate between them.

What sort of extra knowledge might be used? There is no one way of doing this in the literature. One possibility is to continue to add on sign restrictions for more impulses. Thus one can see from figure 1 that imposing a negative effect of an interest rate shock upon output and inflation for ten periods rather than one period would eliminate many of the 1000 models in that figure. Faust (1998) and Uhlig (2005) choose a value of $\theta$ that minimizes a criterion that is a function of the magnitude of the impulse responses $C_{j}^{(k)}$. Kilian and Murphy (2009) impose bounds on the structural coefficients by appealing to plausible bounds on the short-run supply elasticity of oil and the initial impact of oil prices upon activity i.e. not all models should be regarded as equally plausible. Provided it is clear that this is being done then it is simply a matter of deciding if the supplementary criterion is acceptable, although one needs to recognize that non-sign information is being invoked to get a unique model.

Often however there has been a reluctance to utilize such extra information and this has led the strategy of reporting a range of values for the impulse responses drawn from all the models that have been produced e.g. 
as in figure 1. Thus all the impulse responses $C_{j}^{(k)}$ that satisfy the sign restrictions are computed, where $k$ indexes the different values of $\theta$, and then various percentiles such as the $5 \%, 50 \%$ and $95 \%$ are reported. It may seem as if this is emulating the approach when one presents percentiles of a distribution from either a Bayesian or bootstrap experiment. But it is important to recognize that the distribution here is across models. It has nothing to do with sampling uncertainty. Referring to this range as if it is a confidence interval ( something that is very common in the applied literature) is quite false. All you get is a glimpse of the possible range of responses as the model varies. Of course, this might be valuable. Often we do present information about how our answers change as models are varied e.g. Leamer (1978) did this in a regression context with his extreme bounds analysis. But it should not be imbued with probabilistic language. Even if the VAR parameters $A_{1}$ and $\Omega$ were known with certainty there will be a question of how one proceeds whenever there are many $\theta$. There is of course a greater range when one accounts for the uncertainty in $A_{1}$ and $\Omega$, as is often done in this literature e.g. Uhlig (2005) and Peersman (2005), where Bayesian methods are applied to estimate the summative model, but it does not help to understand the model identification issue by confusing these two sources of variation.

Do any difficulties arise in interpreting (say) the median of the impulse responses? Suppose there is a single variable and two shocks, and that we have impulse responses $C_{11}^{(k)}$ and $C_{12}^{(k)}$, where $k$ indexes the models ( values for $\theta$ ). Ordering these into ascending order enables one to find the medians $C_{11}^{\left(k_{1}\right)}=\operatorname{med}\left\{C_{11}^{(k)}\right\}$ and $C_{12}^{\left(k_{2}\right)}=\operatorname{med}\left\{C_{12}^{(k)}\right\}$. But $k_{1}$ may not equal $k_{2}$, and so the model that produced the impulse response that is the median of $\left\{C_{11}^{(k)}\right\}$ may not be the same as that for $\left\{C_{12}^{(k)}\right\}$. Presenting the medians may be likened to presenting the responses to technology shocks from an RBC model, and the monetary shocks from a monetary model, and it is hard to believe that this is a reasonable approach.

Another piece of information presented in papers is a variance decomposition of $\operatorname{var}\left(z_{t}\right)$ into the contributions from various shocks. Often this is done using the medians of the impulse responses. Is this correct? Now a variance decomposition requires that the shocks be defined in the same way i.e. to use a common value of $\theta$ since it is only in this case will the shocks be uncorrelated by design. If shocks are not uncorrelated then a variance decomposition does not make much sense. This issue is not resolved by another common practice that computes the fraction of the variance explained by the 
$j^{\prime}$ th $\operatorname{shock}(j=1, . ., n)$ in the $k^{\prime}$ th model $k(k=1, \ldots, M), \psi_{j}^{(k)}, j=1, . ., n$, and then reports the $n$ medians of $\left\{\psi_{j}^{(k)}\right\}_{k=1, \ldots, M}$.. Since in general these medians will not come from the same model there is nothing which ensures that the $\operatorname{med}\left\{\psi_{j}^{(k)}\right\}$ sum to one across all shocks i.e. the variance is exhaustively accounted for.

One possible alternative that seeks to preserve the idea that a median is a good quantity to present as a summary of the central tendency of impulse responses across models, and which only uses sign restriction information, is a method we proposed in Fry and Pagan (2005). Our solution was to choose that value of $\theta^{(k)}$ that produces impulses which are as close to the median responses as possible. To devise a criterion to do this it is necessary to recognize that the impulses need to be made unit-free by standardizing them. This is done by subtracting off their median and dividing by their standard deviation, where these are measured over whatever set of models has been retained as satisfying the sign restrictions. These standardized impulses are then placed in a vector $\phi^{(l)}$ (in a two variable case $\phi$ is $4 \times 1$ as there are four impulses) for each value $\theta^{(l)}$. Subsequently we choose the $l$ that minimizes $\phi^{(l) \prime} \phi^{(l)}$, and then use that $\theta^{(l)}$ to calculate impulses. Whether this strategy produces a unique $l$ is an empirical question, although in applications we have made it turns out to do so.

In Figure 2 we show what this would produce based on the impulses in Figure 1. Clearly major differences in the effects of an interest rate shock upon output emerge when it is insisted that the shocks must come from a single model. A comparison of the median with the adjusted measure for other shocks does not reveal as great a difference. In Fry and Pagan (2005) we found that applying the method to the data in Blanchard and Quah (1999) produced very little difference when assessing the impact of demand and supply shocks. A number of other papers also report that the results are not too dissimilar e.g. Ruffer et al (2007), Canova and Paustian (2007). It does seem to us however that it is more satisfactory to ensure that the impulses come from the same model rather then getting them from different models, even if in some specific instances the adjustment does not produce major changes. At the very least one needs to check that a failure to insist that shocks come from a single model has not created any distortions. The adjustment is simple to compute. One might also observe that, although the discussion above has been about the median, it also applies to any of the "percentile" measures. 
s:int rate r:gap

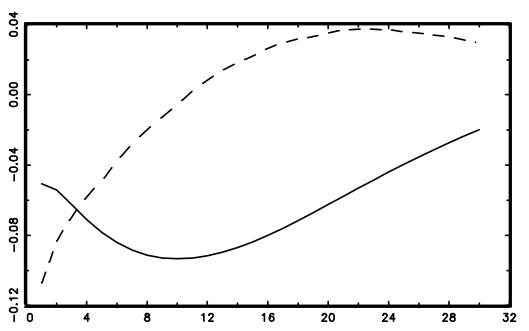

s:cost push r:gap

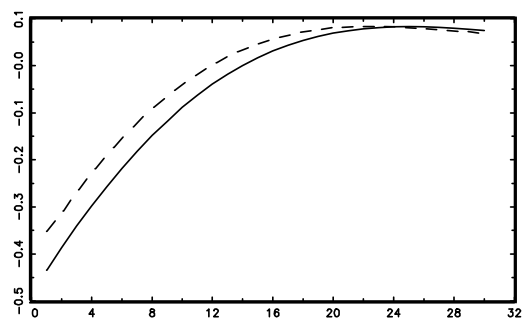

s:demand $r$ :gap

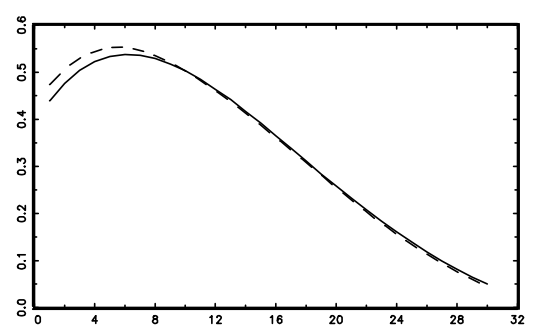

s:int rate $r$ inf
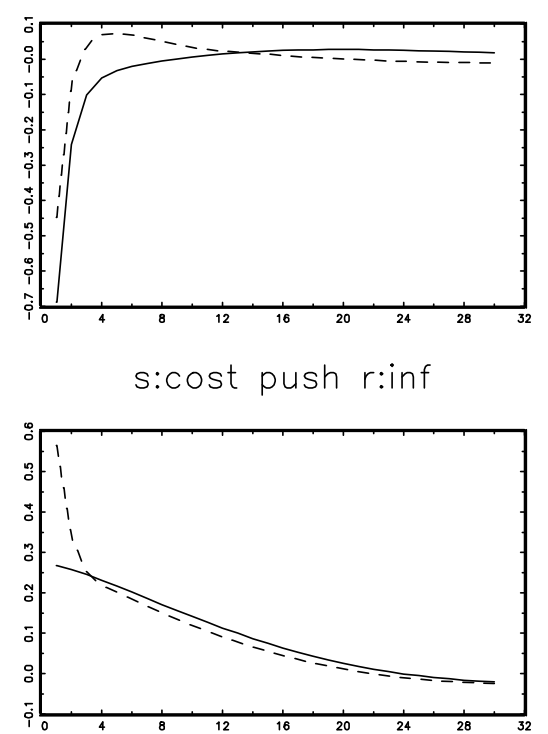

s:demand $r: i n f$

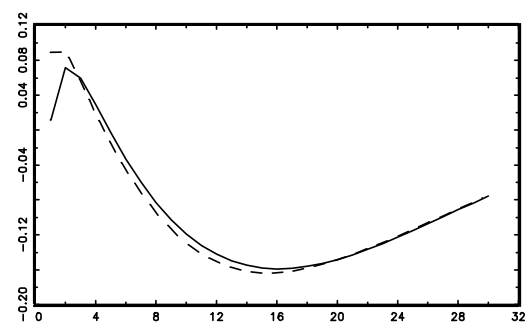

s:int rate $r$ :int

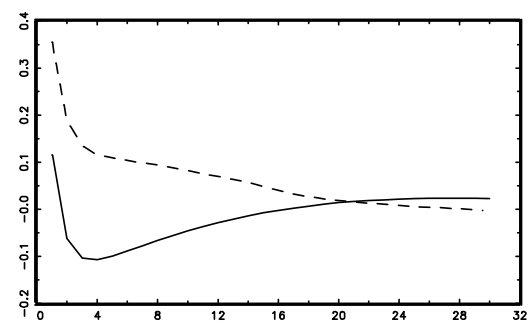

s:cost push r:int

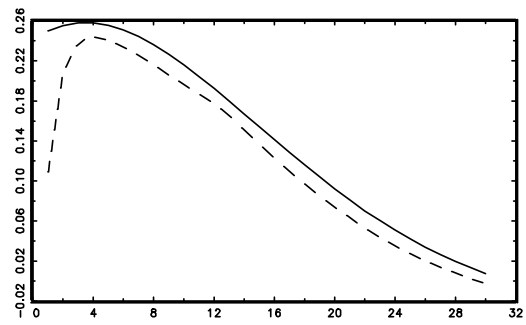

$s: d e m a n d r: i n t$

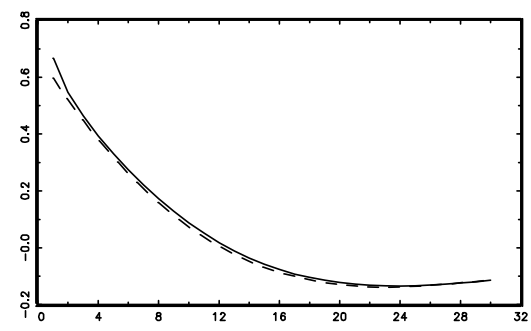

Figure 2: Median impulse response following the suggested rule (solid line) and the median impulse response (dashed line). 


\subsection{Information Provided by Sign Restrictions: Can We Recover Correct Impulse Responses?}

The impression that seems to be present in the literature is reflected in the comment by Paustian (2007, p 1)) that "the researcher will identify a set of impulse responses containing the true one" i.e. whilst there may not be a unique set of responses that are compatible with the sign restrictions, within the collection of impulse responses there will reside the correct ones. To see that this presumption is incorrect we return to the market model and consider a special case where $\beta=1, \gamma=1, \sigma_{D}^{2}=1, \sigma_{S}^{2}=1$, and $\phi_{i j}=0$. It is readily verified that in this case $\operatorname{cov}\left(q_{t}, p_{t}\right)=0$, making $\tau=0 .{ }^{7}$ Then the two curves produced by applying the Givens transform will be

$$
\begin{aligned}
p_{t} \cos \theta-q_{t} \sin \theta & =\sigma_{\eta_{1}} \eta_{1 t}^{*} \\
p_{t} \sin \theta+q_{t} \cos \theta & =\sigma_{\eta_{2}} \eta_{2 t}^{*} .
\end{aligned}
$$

Now one of these curves must be demand and the other supply if the shocks have been identified in that way. Suppose the demand curve is the first. Then we would have $\sigma_{\eta_{1}} \eta_{1 t}^{*}=\varepsilon_{t}^{D}$ and it is necessary that $\sin \theta=$ $-1, \cos \theta=1$ if the true demand shock is to recovered. The first of these conditions implies that $\theta=\frac{3 \pi}{2}$, and this conflicts with the second requirement that $\cos \theta=1$. Now suppose that it is the second equation that is the demand curve. Then we would need $\cos \theta=1$ and $\sin \theta=-1$. Again these are incompatible. Hence there is no value of $\theta$ that will deliver the the correct demand and supply elasticities.

Is there a weaker outcome that we might asset? Paustian (2008) performs Monte Carlo experiments on models where sign restrictions on a set of (primary) variables are imposed to identify the shocks and then the impulses to other (secondary) variables are checked to see if they have the correct sign. He draws two conclusions from the experiments. Firstly, it is likely that the correct signs for the impact of the shocks on the secondary variables will be found if the identified shocks have a dominant influence on the primary variables. Secondly, the more shocks that are identified the greater is the likelihood that the correct signs will be recovered. This leads him to conclude that sign restrictions can reliably recover some qualitative features of impulse responses under certain conditions.

\footnotetext{
${ }^{7} \tau$ can be found as the probability limit of the OLS estimator of the coefficient of $p_{t}$ in the regression of $q_{t}$ on $p_{t}$.
} 
The results he gets can be explained. Since the reduced form VAR shocks are $e_{t}$ and the structural ones are $\varepsilon_{t}$, with the connection being $e_{t}=B_{0}^{-1} \varepsilon_{t}$, when there are no lags and $n=3$ the first "VAR" equation will have the following relation between its error and the structural shocks:

$$
e_{1 t}=b_{0}^{11} \varepsilon_{1 t}+b_{0}^{12} \varepsilon_{2 t}+b_{0}^{13} \varepsilon_{3 t},
$$

where $b_{0}^{i j}$ are the coefficients of $B_{0}^{-1}$. If $\varepsilon_{1 t}$ was known then $b_{0}^{11}$ (the impact response ) could be consistently estimated by regressing $e_{1 t}$ on $\varepsilon_{1 t}$, since the omitted regressors $\varepsilon_{2 t}, \varepsilon_{3 t}$ are uncorrelated with $\varepsilon_{1 t}$. However, $\varepsilon_{1 t}$ is not known and sign restrictions involve combining the VAR errors $e_{j t}$ with weights to extract an estimate $\varepsilon_{i t}^{*}$. In turn this estimate can be written as a combination of the $\varepsilon_{j t}$ :

$$
\varepsilon_{1 t}^{*}=\phi_{1} \varepsilon_{1 t}+\phi_{2} \varepsilon_{2 t}+\phi_{3} \varepsilon_{3 t} .
$$

From (10) it is clear that a regression of $e_{1 t}$ on $\varepsilon_{1 t}^{*}$ will produce a biassed estimator of $b_{0}^{11}$ owing to the simultaneous presence of $\varepsilon_{2 t}, \varepsilon_{3 t}$ in the regressor and the error term of the equation. Of course this bias will decline as the variance of $\varepsilon_{1 t}^{*}$ increases relative to the variance of $b_{0}^{12} \varepsilon_{2 t}+b_{0}^{13} \varepsilon_{3 t}$, and this is the first conclusion Paustian reaches.

To see the second we just need to note that, if a second shock is identified, the regression becomes one of $e_{1 t}$ on $\varepsilon_{1 t}^{*}$ and $\varepsilon_{2 t}^{*}$. There is no certainty but it is likely that the biases will be smaller now than before. If it was the case that $\varepsilon_{2 t}$ had been correctly estimated then it would have been eliminated from the error term of the regression, leaving only $\varepsilon_{3 t}$. So it is likely that, as we estimate more shocks using sign restrictions, the bias will be reduced. Again however this is not a general result as it depends upon the extent to which the shocks have been correctly extracted.

\subsection{Sources of Information for Sign Restrictions}

Generally these have been rather informal although increasingly they have been drawn from DSGE models. Thus the New Keynesian (NK) policy model of the form

$$
\begin{aligned}
y_{t} & =\alpha_{1 y} y_{t-1}+\beta_{1 y} E_{t}\left(y_{t+1}\right)+\gamma_{1 i}\left(i_{t}-E_{T}\left(\pi_{t+1}\right)\right)+\varepsilon_{y t} \\
\pi_{t} & =\alpha_{2 \pi} \pi_{t-1}+\beta_{2 \pi} E_{t}\left(\pi_{t+1}\right)+\gamma_{2 y} y_{t}+\varepsilon_{\pi t} \\
i_{t} & =\alpha_{3 \pi} i_{t-1}+\gamma_{3 y} y_{t}+\beta_{3 \pi} E_{t} \pi_{t+1}+\varepsilon_{i t}
\end{aligned}
$$


is often invoked as a small macro model. If the shocks are not serially correlated it implies a $\operatorname{VAR}(1)$ in $z_{t}^{\prime}=\left[\begin{array}{lll}y_{t} & \pi_{t} & i_{t}\end{array}\right]$. Hence it has been proposed that this model be simulated for a wide range of the structural model parameter values and that the signs of impulses which are robust to such parameter variations be used as the sign restrictions to be applied to the VAR in $z_{t}{ }^{8}$ The sign restrictions in Table 2 would be consistent with that found by simulating the NK model above for a wide range of parameter values. As we will see in the next section this strategy has been increasingly used in the literature. Canova and Paustian(2007) examine it in some detail, simulating data from a DSGE model and then seeing if the correct impulse responses would be recovered. They find that it recovers the shocks reasonably well, provided that enough of these are used and all shocks are identified. They also suggest that focussing on the signs of the $C_{0}$ will largely avoid any difficulties with the use of a VAR as a summative model in that any approximation errors due to unobserved variables show up in the magnitude rather than the signs of impulse responses.

The model-based approach to producing sign restrictions seems a useful way to proceed, as it does not commit the user to the DSGE model, but has the advantage that it restricts the informal approach in a fashion that probably commands reasonable assent. A lot depends on why one is performing the VAR analysis. If one is trying to "discover" what the data says about relations then imposing sign restrictions from (say) the NK model above would not appeal as much, since one would never find (say) that interest rates had a positive impact on inflation in the data. "Puzzles" like this are sometimes the source of productive theorizing and so one should be careful about predetermining outcomes. Of course one check on this is available from the draws that yielded impulse responses that didn't agree with the sign restrictions. If there are a large number of these then one might well conclude that the data is not in favour of the model used to generate the sign restrictions.

\footnotetext{
${ }^{8}$ As we noted earlier in many DSGE models there are latent variables and so that a VAR might not be a good summative model i.e. the impulse responses from the VAR might deviate from those implied by the DSGE model. Kapetanios et al (2007) certainly found large quantitative differences, although it may be that sign restrictions are preserved. A way to check for this is to simulate a long series of data from the DSGE model and fit a VAR, thereby getting $\hat{D}_{j}$. Giving the structural shocks the initial impulses from the DSGE model i.e. $C_{0}^{M}$, the implied impulse responses from the DSGE model, $C_{j}^{M}$, can be compared with those from the $\mathrm{VAR}, D_{j} C_{0}^{M}$. If there is a major difference one should be careful in using a VAR as a summative model.
} 
Sometimes the number rejected is very high e.g. Kilian and Murphy (2009) report only 30860 "successful" models from 1.5 million draws. Peersman and Staub (2006) used the rejected information in this way to assess whether the New Keynesian model was a good description of the data.

\section{Sign Restrictions in Practice}

A very large number of studies on quite a range of topics now exist which utilize sign restrictions. Many more are continuing to appear. It is impossible for us to cover them all. Many of the papers are basically replications of a set of standard ones for different countries and time periods. Hence we will try to select some of the principal papers in what follows so as to show how sign restrictions have been used in practice i.e. to give the flavour of this work. As the discussion given earlier would suggest there is a strong case for requiring that a certain amount of information be provided in sign restriction studies so as to assess them properly. It seems to us that eight items warrant attention.

(i) What model was used to summarize the data and was it appropriate given the data used and the types of shocks analyzed? As we have observed a VAR will not always suffice. A VECM may be needed and, perhaps, a state space form. Fortunately, the methodology of sign restrictions can be easily adapted to any of these forms.

(ii) It is important to provide a summary of the sign restrictions employed in estimation. Ideally these should be like Tables 1 and 2 .

(iii) An account should be given of the number and nature of variables used, whether a single shock or multiple shocks are identified, and whether the shocks are permanent or transitory. If only one shock is identified what method was used to deal with the multiple shocks problem?

(iv) How was the model identification problem dealt with?

(v) If a variance decomposition was used to measure the relative importance of shocks, is the decomposition exhaustive i.e. does the contribution of each shock to the variance sum to unity, as would happen if shocks were uncorrelated? 
(vi) What type of numerical method was used to generate new candidate shocks that are uncorrelated? Mostly this will not be a major issue, except when only a single shock is identified.

(vii) What was the objective of the study? This can have an important impact upon the design of the model and the determination of which shocks need to be measured.

(viii) What is the source of the sign restrictions? Is it from a calibrated theoretical model or based on some loose economic reasoning?

Where appropriate we will structure our discussion about papers in the literature by asking how they respond to the eight items above.

Table 3 provides a quick summary of the studies that appear in the literature characterized by a number of the items mentioned above - viz. whether there are a mixture of sign and other restrictions, whether there are permanent shocks, how many shocks are identified and whether the source of the restrictions comes from informal ideas or from a formal theory-oriented model. This provides a quick overview of the diversity of the studies. As well we classify them according to the main issue being dealt with e.g. the isolation of the effects of technology shocks, monetary policy shocks, fiscal policy shocks etc. It is apparent from this table that sign restrictions have become of increasing interest to applied researchers seeking information about a large range of phenomena.

\subsection{Technology and Productivity}

A crucial distinction has to be made according to whether technology shocks are assumed to be permanent or not. If permanent a second question then arises of whether there is just a single one. If there is a lone permanent shock the standard approach has been to isolate it via long-run restrictions e.g. Gali(1999) worked with two variables - labour productivity, which was assumed to have a unit root, and hours, which did not, while only technology shocks were taken to have a long-run effect on labour productivity i.e. the relevant part of $C_{\infty} \neq 0$. He was interested in what the effect of technology shocks would be upon hours worked in the short-run. The summative model adopted was effectively a VECM, although Gali and others actually used a system composed of $\Delta z_{t}$ and the EC terms $\beta^{\prime} z_{t-1}$ rather than the $\Delta z_{t}$ 
appearing in (1). Pagan and Pesaran (2008) deal with the equivalence of these representations.

Some papers appear where there are two permanent components. This situation arises when there are series among those used in the VECM analysis that are sensitive to relative price changes e.g. Fisher (2007). Some way of distinguishing between the two permanent shocks is therefore needed, if one is to isolate the effects of a pure technology shock, and here some use has been made of sign restrictions for that purpose. Francis et al (2003) begin their analysis by assuming that both labour productivity and hours are unit root processes ( but not co-integrated) and so there are two permanent shocks. The technology shock is assumed to have a non-zero effect on labour productivity in the long-run while the other shock is taken to have a zero effect. This is rather odd since such a difference is what normally distinguishes a permanent from a transitory shock. It has the implication that, for the non-technology shock, a positive impulse response at horizon $j$ must be offset by a matching negative one at some other horizon, in order to make the cumulated responses sum to zero in the long-run. After they perform this analysis Francis et al. move to an alternative approach which seeks to identify the shocks based on sign restrictions. Specifically technology shocks are taken to have both a positive long-run and short-run effect on labour productivity. The effects of non-technology shock effects are not described. Consequently, as noted earlier in our discussion of the "multiple shock problem", it seems unlikely that the two sign restrictions utilized would enable a satisfactory identification. In agreement with Gali they find that the mean ( across models) of the initial impact of the "technology shock" upon hours is negative.

Dedola and Neri (2007) assume that the technology process does not have a unit root and they determine which signs of the impact of a technology shock are "robust" to a variety of DSGE models calibrated with a range of parameter values. They examine these signs for a large number of variables and response horizons. Thus a positive technology shock is generally found to have positive effects on labour productivity, the real wage, output, consumption and investment for up to nineteen periods. Although only one shock is identified with these sign restrictions it seems likely that their use of a very large number of restrictions would substantially ameliorate the multiple shocks problem. ${ }^{9}$ Because technology is assumed to be a stationary

\footnotetext{
${ }^{9}$ They explicitly acknowledge a possible multiple shocks problem during their simula-
} 
process it seems hard to directly compare the conclusions they reach about the impact of technology shocks on hours with Gali's, since the summative models are very different. Because it is not hard to simulate DSGE models with permanent technology shocks it seems odd that a comparative exercise using the same summative model was not performed.

Peersman and Straub (2004) follow a similar strategy, getting sign restrictions from a variety of DSGE models and calibrations of parameters. They differ from Dedola and Neri in identifying four shocks - monetary policy, demand, technology and labour supply. Also, in contrast to Dedola and Neri the sign information used is only that on the contemporaneous impact of the shocks on four variables - real GDP, GDP deflator, short-run interest rate and real wages. They also assume that all variables are stationary. Hours are included in the VAR but no sign restrictions are assumed regarding the impact of technology shocks on this variable. Instead, like most of this literature, their interest is in what the impact of a technology shocks on hours is in the data. The signs of $C_{0}$ ( excluding hours and with variables and shocks listed in the order above) are $\left[\begin{array}{cccc}+ & + & - & ? \\ + & + & + & ? \\ + & - & ? & + \\ + & - & ? & -\end{array}\right]$, and these seem be diverse enough to separate out the shocks. The median is used to compute the impulse responses across models. A technology shock was found to have a positive impact on hours.

\subsection{Fluctuations}

Work on the determinants of fluctuations revolves around a number of questions. One is whether there is a single shock that is the dominant contributor. To look at this one might specify what is believed to be the dominant shock and to then assess how important it is relative to the joint effect of other (unnamed) shocks. Much of the technology literature has been interested in that question. If technology is the only permanent shock then long-run restrictions make most sense as the way to assess it. There is a strange mis-

tions of a DSGE models with four shocks - technology, capital tax, labour supply, and investment. In some models the responses to the first two shocks had identical signs. This lead them to measure a capital tax shock independently of the VAR analysis and to then use it in a VAR. But how this was done is not elaborated on and the results from such a VAR do not seem to be reported. 
conception that there are "biasses" caused by such restrictions these, and often Faust and Leeper (1997) are quoted to defend this statement. This is a mis-reading of that paper - see Levtchenkova et al (1998). It is about approximation errors with the summative model and these would apply in a sign restrictions context as well. There are indeed difficulties with long-run restrictions in that the instruments used in estimation can be very poor, and this can lead to biassed estimators of the structural parameters, but that is something which is capable of being solved with recent work aiming to make inferences robust to weak instruments.

A good deal of the empirical work assessing the contribution of shocks to fluctuations has utilized sign restrictions as a way of identifying the shocks. Peersman (2005) is an early contribution, aiming to study the slowdown of the early 2000s. He estimates a four-variable VAR(3) for the Euro region and the US. The variables are the first difference of the log of oil prices, output growth, consumer price inflation and the short term nominal interest rate. Peersman identifies four shocks - demand, monetary policy and two supply shocks. The first of the supply shocks is due to oil prices and the second is just labelled a non-oil supply-side shock. Restrictions apply to impacts for a number of periods and the $C_{j}$ matrix has the signs $\left[\begin{array}{cccc}+ & - & + & * \\ + & - & - & + \\ + & - & - \\ + & + & -\end{array}\right]$, where shocks and variables are ordered as listed above and the shocks are positive. ${ }^{10}$ Note that a positive non-oil supply side shock is the equivalent of a negative oil price shock, so that the only way to differentiate between the two shocks is the effect on the price of oil i.e. the cell marked as "*". Peersman therefore assumes that an oil price shock has a greater effect upon oil prices than a non-oil price shock. Givens matrices were generated and 1000 models were produced. On average, 109 values of $\theta$ have to be drawn to find a single set of impulses which satisfy all restrictions.

Peersman utilizes the median impulse responses for all his empirical analysis of the early 2000s slowdown. It was shown in Fry and Pagan (2007) that his median impulse responses come from very different models and so the shocks are not uncorrelated. Moreover, utilizing their method for getting as close as possible to the median, while retaining a single model, results in a

\footnotetext{
${ }^{10}$ The number of periods that the same signs are assumed to persist for varies with the shock but the upper limit is three periods.
} 
very contribution of the contemporaneous shocks to the slowdown.

Ruffer et al (2007) and Sanchez (2007) proceed in much the same way. The first looks at the contributions to fluctuations in ten Asian countries and the latter to fifteen emerging economies. In the first paper the variables in the VAR are industrial production, consumer prices, real money balances and the real effective exchange rate, while shocks are supply (technology), real demand, monetary policy and an un-named one. Rather than imposing sign restrictions on the impulse responses, they invoke them on the "product" of such responses. Thus a supply side shock is taken to result in a negative comovement between output and inflation while demand and monetary shocks produce a positive co-movement. The latter are differentiated since a demand shock is taken to imply a negative co-movement between real money balances and inflation while a monetary shock produces a positive one. These comovements are assumed to hold for six periods although there seem to have been cases where, after three million draws of the Givens matrices, there was a failure to find any models that satisfied the restrictions, in which case the number of periods that the signs had to hold for were reduced.

Only four shocks are identified and effects on the exchange rate are not used. There is no difficulty in handling "product" restrictions as this does not change the method of re-combining the base shocks, just that "success" is being judged by a different criterion Another novelty in Ruffer et al was the use of a VARX as the summative model, where the exogenous (X) variables were foreign ( global interest rates, equity prices and the price of oil and non-oil commodities) along with some dummy variables to capture the Asian crisis of 1997-1998. One might have included foreign variables in extra VAR equations but, since Ruffer et al. were not interested in identifying separate foreign shocks, it is easiest to treat them as extra regressors in the VAR equations containing domestic variables only.

Because the fourth shock is not identified one might well find a "multiple shocks problem" and, indeed, they make reference to the fact that this did happen, but offer no comment on what they did about it. Perhaps the most interesting conclusion from the study was that foreign shocks were the major drivers of fluctuations in these ten Asian countries.

The second of the papers derives sign restrictions from simulating a DSGE model under various quantifications of the parameters. Only restrictions robust to the parameter values were chosen. These experiments suggested that one should only concentrate upon the signs of the initial impacts of the shocks i.e. the signs in $C_{0}$. Variables in the first VAR worked with were output, 
prices, exports and imports, while a later one adds on the real exchange rate and the interest rate. ${ }^{11}$ The shocks are technology, preferences, money and a risk premium. With the exception of the effect of the risk premium upon output, these shocks had distinct sign-patterns in $C_{0}$ (even when the six variable VAR was used) and so there seems good reason for thinking that all shocks were identified. Some percentiles of the model impulses were presented as well as a variance decomposition. It is unclear what was used to compute the latter. Since seven of the 10 economies of the previous paper appear in the sample, it is surprising that a principal conclusion was that fluctuations were mostly a result of domestic rather than foreign shocks, as that is in contrast to what Ruffer et al. (2007) found. Of course the variables in the VAR are different, but it may also be a consequence of using DSGE-inspired restrictions, since Justiniano and Preston (2008) also found the same thing when applying DSGE models to a number of small open economies.

Canova (2005) studies fluctuations in the Latin economies included in Sanchez's data set. He is interested in the question of how much US shocks transmit to them. He first identifies US shocks using sign restrictions before using them as regressors in VARs for Latin American countries. US financial shocks turn out to be important, but not US real shocks. It is hard to know what to make of this study since nowhere does Canova deal with how he solved the model identification problem. Indeed, since he only uses restrictions on contemporaneous correlations, it is hard to believe that these would produce a unique model. Yet one needs that as the constructed US shocks used as regressors could be very different with other observationally equivalent models.

\subsection{Monetary and Fiscal Policy}

Some of the earliest work using sign restrictions focussed on monetary policy, in particular the response of output to monetary policy shocks. Examples are Faust (1998), Canova and De Nicoló (2002) and Uhlig (2005). Common to them is a VAR in levels and sign restrictions for monetary policy similar to those in Table 2. Differences are in the number of variables in the VAR and its order, this depending partly on whether monthly or quarterly data is used. In addition Canova and De Nicoló identify three shocks - technology,

\footnotetext{
${ }^{11}$ In fact there are also foreign variables and these were handled via a VARX model as in Ruffer et al (2007).
} 
government and a monetary shock- while the other two authors seek to only isolate a monetary policy shock.

Faust (1998) does not choose a unique model but is interested in examining propositions such as monetary policy having little effect on fluctuations. Therefore, evidence against this proposition would be a model in which a high fraction of the variance of output is explained by the monetary policy shock. Hence he chooses that model from the complete set which satisfies restrictions involving the maximum contribution of monetary policy shocks to fluctuations at a nine year horizon. Thus it is the range of results from the models that is of interest to him. He concludes that the result from recursive models in Christiano et al (1997) that monetary policy shocks account for only a small share of the variance of output is not supported if a six variable VAR ( the same as used by Christiano et al) was adopted, but it does seem to be when the VAR is expanded to include thirteen variables. In general the magnitudes of the effects of monetary policy were sensitive to what sign restrictions were imposed.

Canova and De Nicoló (2002) use the signs of cross correlations of variables at various time horizons - what we previously called product rules. Unlike Faust who worked with informally derived sign restrictions, they construct theirs from a monetary model with limited participation. They are careful to document where multiple monetary shocks were are found and, when computing variance decompositions, ensured that the shocks used were uncorrelated prior to the calculation. They find that the impact of monetary policy shocks on output can be large.

Uhlig identifies only a monetary shock stating that there is no reason to find the other fundamental innovations. The sign restrictions used are that a contractionary monetary shock would reduce inflation and non-borrowed reserves, but increase the short-run interest rate for five periods. A solution to the model identification problem is proposed that involves the use of a penalty function on the impulse responses which favours larger responses of the correct sign. However, this is not used in the results he presents. Instead he presents upper and lower bounds for each impulse response function across the models that were retained. To deal with the multiple shocks problem all are retained and treated as equally likely. His variance decompositions show that monetary policy shocks account for between five and ten per cent of the variance of output, well below what Faust settles on with his six variable VAR. However, this calculation is based on the median impulse responses and therefore suffers from the potential problem that the shocks are not 
uncorrelated.

Following the approach of Uhlig there are several papers that identify the effects of monetary policy shocks in different economies and on different sectors. Rafiq and Mallick (2008) examine the effects of monetary policy on the output of Germany, France and Italy motivated by the idea that common output responses across the three countries imply suitability for a currency union. Mountford (2005) focuses on the effects of monetary policy on the UK while Vargas-Silva (2008) investigates the effect of a monetary policy shock on the U.S. housing market.

Rafiq and Mallick (2008) work with a VAR in real gdp, the gdp deflator, commodity prices, M1, and the real effective exchange rate as the summative model. The sign restrictions used to identify the monetary shock is that a contractionary shock increases interest rates, reduces output, appreciates the exchange rate, reduces inflation and the money supply for at least two quarters. Experiments were also done where these effects were taken to hold for up to ten quarters. Monetary policy is found to have small effects. In their sensitivity analysis they experimented Uhlig's penalty function approach to produce a unique model and attempted to identify a wider range of shocks, including demand, supply and an oil price shock. Sign restrictions used in the latter case for the demand and supply shocks are those of Table 1, while an oil price shock is taken to positively affect commodity prices. Such a minimal number of restrictions is unlikely to solve the multiple shocks problem.

Mountford (2005) is another paper adopting the approach of Uhlig, but with a focus on the effects of monetary policy on the U.K. macro-economy. He finds that monetary policy has a small role in the macro-economy. Four shocks are identified in a system of six variables, with the shocks labelled as a monetary policy shock, an oil price shock, a supply shock, and a nonmonetary aggregate demand shock, leaving two shocks unidentified in each draw. His summative model is a VAR in levels, and although Mountford notes the possibility of the presence of cointegration, he does not formally attempt to model this. The chosen impulse responses are those which minimise the Uhlig penalty function. Mountford (2005) alludes to the possibility of a multiple shocks problem.

As is the case in the wider VAR literature, applications to fiscal policy are less common than those to monetary policy. This is partly due to the difficulty of identification of fiscal policy within the VAR framework. Blanchard and Perotti (2002) developed a method of identification based on institutional detail and calibrated elasticities which aim to separate out pure fiscal 
policy changes from those due to built-in stabilizers. Mountford and Uhlig $(2005,2008)$ argued that if a business cycle shock is properly accounted for in the VAR, then the pure fiscal policy shocks will be uncorrelated with it and hence this produces a solution to the issue. The use of sign restrictions would thus be appropriate for this case. Canova and Pappa (2007) and Dungey and Fry (2009) build on that position.

Mountford and Uhlig $(2005,2008)$ estimate a 10 variate model containing GDP, private consumption, total government expenditure, total government revenue, real wages, private non-residential investment, the interest rate, reserves, a producer price index and the GDP deflator. They identify four shocks. These are a business cycle shock, a monetary policy shock, a government revenue shock and a government spending shock. Again, a minimal number of sign restrictions are imposed and they are not derived from any particular model. A business cycle shock is assumed to have a positive effect on government revenue, GDP, consumption and non-residential investment while a monetary policy shock has a positive effect on interest rates and negative effect on reserves and prices. The fiscal shocks are identified with government revenue and expenditure responding positively to revenue and expenditure shocks. Once again the minimalist nature of these restrictions raises the possibility that there is insufficient information to discriminate between the shocks. Mountford and Uhlig use the Uhlig penalty function approach to reduce the retained models set.

Canova and Pappa (2007) examine the effects of fiscal policy shocks on price differentials between members of a monetary union by focussing on of nine European countries and most of the states of the United States. Their summative model is a panel VAR. Some variables measure the differential between the member country and the union aggregate. These are the price level, real per capita GDP, employment level. As well member per capita government revenues and expenditures appear in the VAR variable set. The data frequency is annual. Some exogenous variables also appear in the VAR including the common interest-rate and oil prices. Their sign restrictions stem from DSGE models, and provide the information to identify three types of shocks. The first of these is a government expenditure shock, which results in a positive deficit and an increased co-movement in member outputs. Second there is a budget balanced shock where the deficit remains unchanged and negative co-movement of member outputs. Third is a taxation shock resulting which produces negative co-movements in member deficits and output. The method used by Canova and Pappa (2007) to determine the shocks is 
the same as that used in Canova and De Nicoló (2002).

A model jointly specifying fiscal policy, monetary policy and other economic shocks is explored in Dungey and Fry (2009) for New Zealand. Both permanent and transitory shocks are thought to be present and the summative model is taken to be a VECM in observable variables. Following Pagan and Pesaran (2009) permanent shocks are taken to be the shocks in particular structural equations, meaning that the error correction terms are excluded from those equations, thereby freeing up instruments to estimate those structural equation parameters. ${ }^{12}$ Non-fiscal transitory shocks are also present in the VECM system and these shocks are identified by block-recusive restrictions. Finally, sign restrictions are used to identify fiscal policy shocks. The sign information is that GDP rises in response to a positive government expenditure shock while a positive taxation shock causes GDP to fall. Because the signs of these responses are exact opposites there is a difficulty in disentangling (say) positive expenditure shocks from negative tax shocks. Extra quantitative information is therefore invoked to perform the separation. This takes the form that an expenditure shock has a larger initial effect than a tax shock.

\subsection{Exchange Rates}

There are a number of papers concerned with various issues connected with exchange rates where sign restrictions have been employed. Over-shooting of exchange rates has become a staple in international finance, but empirical work done with recursive VARs such as Eichenbaum and Evans (1995) suggests that it is significantly "delayed", and the peak response is some years after monetary movements rather than in the very short run. This might come from the fact that these recursive SVARs also find that a monetary contraction increases the price level - the "price puzzle". Thus it is natural to see if the timing of the peak response is a consequence of a poor identification strategy for a monetary shock.

Faust and Rogers (2003) and Scholl and Uhlig (2005) deal with this. It is not entirely clear how Faust and Rogers proceed and models seem to be selected not only on sign restrictions but by minimizing their conflict with UIP. Scholl and Uhlig (2008) restrict themselves to sign restrictions. Variables used in their VAR are those in Eichenbaum and Evans (1995), namely

\footnotetext{
${ }^{12}$ There are also exogenous permanent shocks that are connected to the foreign sector.
} 
measures of (monthly) relative industrial production for the countries in the exchange rate, relative interest rates, US non-borrowed reserves, the US consumer price index and the nominal exchange rate. They identify only monetary shocks utilizing that fact that negative U.S. monetary shocks have a negative effect on prices, non-borrowed reserves and a positive impact on interest rates for a year. The long period of time likely eliminates the multiple shocks problem, but there are a lot of shocks in this VAR so it is hard to know for sure. Price puzzles are ruled out by the sign restrictions but the over-shooting peak is still found to occur a few years out. They report the median impulses, and use these to calculate variance decompositions for the exchange-rate explained by the US and foreign monetary policy shocks. One difficulty in analyzing these studies is that the Dornbusch over-shooting prediction is in response to a permanent monetary shock. This means that the summative model should allow for such a shock. Faust and Rogers certainly do so as they work with money growth in the VAR. But Scholl and Uhlig use the ratio of non borrowed reserves to total reserves and consider only transitory movements in the ratio.

A similar issue arises in other studies that examine the response of the exchange rate to various shocks and where a number of shocks are identified. Clarida and Gali (1994) used a long-run restriction that a nominal shock would not affect the real exchange rate as an identifying strategy in a three variable VAR. All their variables are measured in differences so that all shocks are permanent. Farrant and Peersman (2006) propose to identify the same three shocks - supply, demand and nominal - using sign restrictions based on responses for four periods ( output and prices) and one for the real exchange rate. But they use the same VAR as Clarida and Gali so the nominal shock must have a permanent effect on the real exchange rate. They contrast their results on this with Clarida and Gali, but in both cases it reflects the design of the summative model. It is not apparent why it is attractive to treat the nominal shock as permanent and it would seem better to work with a summative model that had one or two permanent shocks along with a single transitory (nominal) shock which has a zero long-run effect on the real exchange rate by its very definition.

An (2006) looks at the pass through of exchange rate movements to prices using a VAR in 8 variables - the price of oil, short-run interest rate, output gap, nominal effective exchange rate, foreign prices of exports and three price indices at separate stages of distribution. Only one shock is identified- the exchange rate shock. Sign restrictions are that output, interest rates and 
prices all react non-negatively to a depreciation while the reaction of export prices is non-positive. Oil is measured in US dollars in an attempt to make it invariant to exchange rates. The VAR is fitted to data on eight countries (separately) and is of order six due to the use of monthly data. Median impulses are used and a variance decomposition is performed, although it is not clear how that was done. Incomplete pass through was observed and the biggest effects are on import prices, then producer prices, and finally the CPI. Given that there are eight shocks in the model, and only one of these is identified, there must be some concerns about the multiple shocks problem, but this was not addressed. One might question the summative model as well since we would expect a unit root in the nominal exchange rate and it is extremely likely that this is so for price levels as well. In any DSGE model one would have the changes in these variables so that the design of the summative model here does not seem appealing.

Bjornland and Halvorsen (2008) consider whether interest rate decisions depend on the exchange rate in a VAR with five shocks- real exchange rate, foreign interest rate, output, inflation and a domestic monetary policy shock. They use a recursive structure to identify all shocks except for domestic monetary policy. Since the exchange rate and interest rate are regarded as being simultaneously determined, recursive restrictions cannot identify an interest rate rule whenever an exchange rate appears in it. They therefore impose a sign restriction that a contractionary monetary policy rule will produce an immediate appreciation in the exchange rate. These assumptions should then be enough to identify monetary shocks and the paper is a good example of the combined use of parametric and sign restrictions. A VAR is fitted to six countries and the median impulses show little evidence of delayed overshooting. There is mixed evidence about whether exchange rates do influence interest rate decisions.

Lewis (2007) examines whether the real appreciation of the US dollar against the Euro in the 1990s was due to stronger productivity growth in the U.S. tradeables sector. A two country, two sector DSGE model is constructed where there are economy wide and sectorial technology shocks as well as demand and nominal (monetary policy) shocks. Only one set of parameter values is used to generate impulse responses that are the source of the sign restrictions. A VAR is fitted to four series that are the log differentials between US and Euro series. These were real GDP, traded good prices, non-traded goods prices and the real exchange rate. All series were taken to be $I(1)$ and with no co-integration the summative model had them all 
appearing in differenced form. Here there is an inconsistency with the DSGE model. All shocks in the VAR have been permanent effects but the sign restrictions found from the DSGE model are for transitory shocks. Lewis, Table 3, gives enough sign restrictions to identify the shocks (these hold for four quarters except for the effects on the real exchange rate). Median impulses and variance decompositions are used and it is found that sectorial technology shocks explain about one fifth of the variation in the real exchange rate. ${ }^{13}$ What is striking however is that around one half of the variation is due to nominal shocks, something out of line with the rest of the literature. Since there is no risk premium shock in the model, variation in the nominal exchange rate ( and hence the real rate) is probably being ascribed to nominal shocks by default.

\subsection{Miscellaneous}

Hau and Rey (2004) are interested in whether the portfolio re-balancing associated with unhedged foreign equity leads to changes in equity returns, equity flows and the exchange rate. They have a three variable VAR involving those three variables for the US relative to five other countries. Data are at a monthly frequency. Three shocks are to be identified-equity price, exchange rate and equity flow. Portfolio re-balancing after equity and exchange rate shocks implies sign restrictions on the correlations between the variables while an equity flow shock also has predictions for the correlations as well. Six sign restrictions are imposed. The problem then is what one can learn from the study. Their conclusion is that the data "..are consistent with a dynamic rebalancing.." but this seems to reflect a mis-conception about the operation of sign restrictions, as seen in the following quotation " "The decomposition of the variance-covariance matrix uses only three free parameters ( three rotation angles) to fit a total of six theoretical moments, Rejection of one or more of the six conditional correlation implications by the data is therefore possible" (p 130). This is incorrect. The six sign restrictions are needed to identify the six unknown coefficients in the SVAR. The three "rotation angles" $\left(\theta_{1}, \theta_{2}, \theta_{3}\right)$ are not estimated from the data at all. Now it is certainly possible that one could find that there are many models which are inconsistent with the sign restrictions, and that would indicate that there is

\footnotetext{
${ }^{13}$ Lewis notes in Table 4 that the contribution of the shocks to the variance of the real exchange rate sum to more than unity, a feature we noted earlier was likely to occur when these come from disparate models.
} 
a conflict of the data with portfolio re-balancing. But the impulse responses presented are those from a unique model chosen from the set of models that satisfy the sign restrictions by using Uhlig's penalty function. Consequently, portfolio balancing is imposed and one cannot learn anything about its existence from the quantitative work they perform. One might learn something about the strength of the effect by considering the magnitudes of the impulse responses selected, but these are biassed towards being strong by the use of Uhlig's criterion.

Fujita (2009) estimates a trivariate VAR consisting of quarterly US labour market data on the job separation rate, the job finding rate and vacancies. One shock is to be identified - a negative "aggregate" shock. Given that there are identities linking the three basic variables to gross job separations, gross hires and the level of unemployment, it is possible to trace out impulse responses to those variables after the VAR has been estimated. The negative aggregate shock implies that unemployment changes are non-negative for $K$ periods and vacancies are not raised initially. These constitute the sign restrictions to identify the shock. As in other studies there is a potential multiple shock problem and Fujita (2009) responds to this by retaining all of them, arguing that one is thereby getting the "average effect" of the shock. This does not seem entirely satisfactory if there are many instances of this occurring. Percentiles are presented in response to the multiple models problem. A key element in the study is that the job separation rate is being treated as endogenously determined rather than made exogenous as in most models analyzing labour market dynamics, so that the SVAR being estimated is novel. If one made the separation rate exogenous then unemployment dynamics would be quite different.

Eickmeier et al. (2000) consider how bank loans respond to supply, demand and monetary shocks in Germany and the Euro area. Four variables appear in the VAR- real gdp, an interest rate, the price level and the stock of outstanding bank loans. Sign restrictions are like those on Tables 1 and 2 ( initially and for one period ahead) and no prediction is made about their impact on loans. Since only three shocks re identified there is clearly a possibility of a multiple shock problem and they allude to this in the paper, but seem to just retain all the shocks. They work with 500 models that satisfy the sign restrictions. To get these required 11515 draws for Germany and 2616 for Europe which might suggest that the model is not that compatible with German data. They present variance decompositions which point to fairly equal contribution of shocks to loans. It is unclear how these decom- 
positions were done given that there is a fourth unidentified shock so there is no reason to think it is uncorrelated with the three identified shocks.

Jarociński and Smets are interested in the determinants of US house prices. They have nine variables in a VAR- level of interest rate, interest rate spread, house investment to gdp, real consumption, real GDP, the gdp deflator, real house prices, commodity prices and the money supply. These are all in logs except for the interest rates. There is also a version that uses differences of (the logs of) GDP, consumption, the GDP deflator, commodity prices and money, and in which all differenced variables are measured relative to their steady state values. The latter summative model is then estimated using Bayesian methods with a prior on the steady state values and a Minnesota prior for the dynamics. The latter seems odd as it implies a unit root in the series but, as these are growth rates, that does not seem appropriate. In any case this summative model is introduced but not used much in the paper. Three shocks are identified - housing demand, monetary policy and a "spread" shock. Restrictions are a combination of parametric and sign. There is not much discussion of the other six shocks and how these are handled. This seems important since it was found that the three identified shocks had no influence on output, and that the housing demand shock was the dominant contributor to housing investment and house prices.

\section{Conclusion}

When sign restriction work first began it was mainly about the identification of a single shock. Since then it has become popular to identify multiple shocks. Moreover the range of applications has grown from the initial focus on monetary policy. Given that sign information is rather weak we suspect that it is best to utilize the restrictions in conjunction with parametric restrictions and that seems to be an emerging tendency as well. A number of other themes also seem to be developing. One is that contemporaneous restrictions might be preferable to imposing restrictions on longer lags. Another is that DSGE models are a useful way of finding out likely sign restrictions, particularly as the number of variables in the VAR grows. We have tried to show these tendencies in the review, and have also argued that more care often needs to be taken in devising the model that is to summarize the data, a clear statement about whether shocks are permanent or transitory should be provided, and an account of how the multiple models and multiple shocks 
were dealt with must be present in the research. In some instances the latter have not been well understood and often the responses to them have been not well documented.

On balance, we do feel that sign restrictions have provided a useful technique for quantitative analysis. There are a number of instances in which variables are simultaneously determined and it is hard to justify any parametric restrictions to resolve the identification problem e.g. interest rates and exchange rates. In these cases sign restrictions appeal. In other situations such as isolating monetary policy, it seems more likely that using institutional knowledge to provide parametric restrictions would be a better way to proceed. This points to the fact that combinations of restrictions are likely to be what we will need to use in the future to carry out good applied work.

\section{References}

An, L. (2006), "Exchange Rate Pass-Through: Evidence Based on Vector Autoregression with Sign Restrictions", manuscript, University of Kentucky.

Bjornland, H. and J. Halvorsen (2008), "How Does Monetary Policy Respond to Exchange Rate Movements? New International Evidence", Norges Bank Working Paper \#2008/15.

Blanchard, O.J. and R. Perotti (2002), "An Empirical Characterization of the Dynamic Effects of Changes in Government Spending and Taxes on Output", Quarterly Journal of Economics, 117, 1329-1368.

Blanchard, O.J. and D. Quah (1989), "The Dynamic Effects of Aggregate Demand and Supply Disturbances", The American Economic Review, 79, 655-673.

Canova, F. (2005) "The Transmission of US Shocks to Latin America", Journal of Applied Econometrics, 20, 229-251.

Canova, F. and G. de Nicoló (2002), "Monetary Disturbances Matter for Business Fluctuations in the G-7", Journal of Monetary Economics, 49, 1131-1159.

Chari, V.V., P.J. Kehoe and E.R. McGrattan (2008), "Are Structural VARs with Long-Run Restrictions Useful in Developing Business Cycle Theory?", NBER Working Paper \#14430.

Cho, S. and A. Moreno (2006), "A Small-Sample Study of the New Keynesian Macro Model", Journal of Money, Credit and Banking, 38, 1461-1481. 
Canova, F. and E. Pappa (2007), "Price Differentials in Monetary Unions: The Role of Fiscal Shocks", Economic Journal, 117, 713-737.

Canova, F. and M. Paustian (2007), "Measurement with Some Theory: Using Sign Restrictions to Evaluate Business Cycle Models", manuscript, ICREA_UPF.

Christiano, L.J., M. Eichenbaum, and C. Evans (1997), "Monetary Policy Shocks: What Have We Learned and to What End?", Manuscript, Federal Reserve Bank of Chicago.

Clarida, R. and J. Gali (1994), "Sources of Exchange Rate Fluctuations: How Important are Nominal Shocks?", Carnegie-Rochester Conference on Public Policy, 41, 1-56.

Dedola, L. and S. Neri (2006), "What Does a Technology Shock Do? A VAR Analysis with Model Based Sign Restrictions", ECB Working Paper \#705.

Dungey, M. and R.A. Fry, (2009), "Identifying Fiscal and Monetary Policy in a Structural VAR", Economic Modelling, 26, 1147-1160.

Eichenbaum, M. and C.L. Evans, (1995), "Some Empirical Evidence on the Effects of Shocks to Monetary Policy on Exchange Rates", The Quarterly Journal of Economics, 110, 975-1009,

Eickmeier, S., B. Hofmann and A. Worms (2009), "Macroeconomic Fluctuations and Bank Lending: Evidence for Germany and the Euro Area", German Economic Review, 10, 193-223.

Farrant, K. and G. Peersman (2006), "Is the Exchange Rate a Shock Absorber or a Source of Shocks? New Empirical Evidence", Journal of Money, Credit and Banking, 38, 939-961

Faust, J. (1998), "The Robustness of Identified VAR Conclusions about Money", Carnegie-Rochester Series on Public Policy, 49, 207-244.

Faust, J. and E.M. Leeper (1997), "When Do Long-Run Identifying Restrictions Give Reliable Results?", Journal of Business and Economic Statistics, 15, 345-353.

Faust, J. and J.H. Rogers (2003), "Monetary Policy's Role in Exchange Rate Behavior", Journal of Monetary Economics, 50, 1403-1424.

Fisher, J.D.M. (2006), "The Dynamic Effects of Neutral and InvestmentSpecific Technology Shocks", Journal of Political Economy, 114, 413-451.

Fry,R. and A. R. Pagan (2005), "Some Issues in Using VARs for Macroeconometric Research", CAMA Working Paper \#19.

Francis, N., M.T. Owyang and J.E. Roush (2005), "A Flexible FiniteHorizon Identification of Technology Shocks", Board of the Governors of the 
Federal Reserve System, International Finance Discussion Papers \#832.

Fry, R.A. and A.R. Pagan (2005), "Some Issues in Using VARs for Macroeconometric Research", CAMA Working Paper \#19.

Fry, R.A. and A.R. Pagan (2007), "Some Issues in Using Sign Restrictions for Identifying Structural VARs", NCER Working Paper \#14.

Fujita, S. (2009), "Dynamics of Worker Flows and Vacancies: Evidence from the Sign Restriction Approach", Journal of Applied Econometrics, forthcoming.

Gali, J. (1999), "Technology, Employment, and the Business Cycle: Do Technology Shocks Explain Aggregate Fluctuations?", The American Economic Review, 89, 249-271.

Grilli, V. and N. Roubini (1995), "Liquidity and Exchange-Rates: Puzzling Evidence from the G-7 Countries", manuscript, Yale University.

Grilli, V. and N. Roubini (1996), "Liquidity Models in Open Economies: Theory and Empirical Evidence", European Economic Review, 40, 847-859.

Hau, H. and H. Rey (2004), "Can Portfolio Rebalancing Explain the Dynamics of Equity Returns, Equity Flows and Exchange Rates", American Economic Review, 94, 126-133.

Jarociński, M. and F.R. Smets (2008), "House Prices and the Stance of Monetary Policy", Federal Reserve Bank of St Louis Review, July/August 2008, 339-365.

Justiniano, A. and B. Preston (2008), "Can Structural Small Open Economy Models Account for the Influence of Foreign Disturbances?", NBER Working Paper \#14547.

Kapetanios, G., A.R. Pagan and A. Scott (2007), "Making a Match: Combining Theory and Evidence in Policy-Oriented Macroeconomic Modelling", Journal of Econometrics, 136, 565-594.

Kilian, L. and D. Murphy (2009), "Why Agnostic Sign Restrictions are Not Enough: Understanding the Dynamics of Oil Market VAR Models", manuscript, University of Michigan.

Leamer (1978), Specification Searches and Ad-Hoc Inference for Nonexperimental Data, John Wiley, New York

Levtchenkova, S. and A.R. Pagan and J.C. Robertson (1998), "Shocking Stories", Journal of Economic Surveys, 12, 507-532.

Mountford, A. (2005), "Leaning into the Wind: A Structural VAR Investigation of UK Monetary Policy", Oxford Bulletin of Economics and Statistics, 67, 597-621. 
Mountford, A. and H. Uhlig (2005), "What are the Effects of Fiscal Policy Shocks", Discussion Paper 2005-039, SFB 649, Humboldt-Universitat, Berlin.

Mountford, A. and H. Uhlig (2008), "What are the Effects of Fiscal Policy Shocks?", NBER Working Paper \#14551.

Pagan, A.R. and M.H. Pesaran (2008), "Econometric Analysis of Structural Systems with Permanent and Transitory Shocks", Journal of Economic Dynamics and Control, 32, 3376-3395.

Pagan, A.R. and J. Robertson, (1998), "Structural Models of the Liquidity Effect", Review of Economics and Statistics, 80, 202-217.

Paustian, M. (2007), "Assessing Sign Restrictions" The B.E. Journal of Macroeconomics, 7, 1-37.

Peersman, G. (2005), "What Caused the Early Millenium Slowdown? Evidence Based on Autoregressions", Journal of Applied Econometrics, 20, 185-207.

Peersman, G. and R. Straub (2004), "Technology Shocks and Robust Sign Restrictions in a Euro Area SVAR", ECB Working Paper \#373. ${ }^{14}$

Peersman, G. and R. Straub (2009), "Technology Shocks and Robust Sign Restrictions in a Euro Area SVAR", International Economic Review, $50,727-750 .^{15}$

Peersman, G. and R. Straub (2006), "Putting the New Keynesian Model to a Test", IMF Working Paper, 06/135.

Preston, A.J. (1978), "Concepts of Structure and Model Identifiability for Econometric Systems" in A.R. Bergstrom et al., Stability and Inflation (Wiley, 1978), 275-297.

Quenouille, M.H. (1957), The Analysis of Multiple Time Series, Griffin's Statistical Monograohs and Course No 1 (Griffin, London).

Rafiq, M.S. and S.K. Mallick (2008), "The Effects of Monetary Policy on Output in EMU3 A Sign Restriction Approach", Journal of Macroeconomics, 30, 1756-1791.

Rubio-Ramirez, J.F., D.F. Waggoner and T. Zha (2005), "Markov-Switching Structural Vector Autoregressions: Theory and Application", Working Paper \#2005-27, Federal Reserve Bank of Atlanta.

Ruffer, R., M. Sanchez and J-G Shen (2007), "Emerging Asia's Growth and Integration: How Autonomous are Business Cycles", ECB Working Pa-

\footnotetext{
${ }^{14}$ delete this when changed to 2009

${ }^{15}$ Change peersman and staub 2004 to 2009
} 
per \#715.

Sanchez, M. (2007), "What Drives Business Cycles and International Trade in Emerging Market Economies?", ECB Working Paper \#730.

Scholl, A. and H. Uhlig (2005), "New Evidence on the Puzzles: Results from Agnostic Identification of Monetary Policy and Exchange Rates", Discussion Paper 2005-037, SFB 649, Humboldt-Universitat, Berlin.

Scholl, A. and H. Uhlig, (2008), "New Evidence on the Puzzles: Results from Agnostic Identification on Monetary Policy and Exchange Rates", Journal of International Economics, 76, 1-13. ${ }^{16}$

Shapiro, M.D. and M.W. Watson (1988), "Sources of Business Cycle Fluctuations", in S. Fischer (ed) NBER Macroeconomics Annual 1988, 111-148.

Sims, C.A. (1980), "Macroeconomics and Reality", Econometrica, 48, 148.

Uhlig, H. (2005), "What are the Effects of Monetary Policy on Output? Results from an Agnostic Identification Procedure", Journal of Monetary Economics, 52, 381-419.

Vargas-Silva, C. (2008), "Monetary Policy and US Housing: A VAR Imposing Sign Restrictions", Journal of Macroeconomics, 30, 977-990.

Wallis, K.F. (1977), "Multiple Time Series and the Final Form of Econometric Models", Econometrica, 45, 1481-1497.

Wold, H.O. (1951), "Dynamic Systems of the Recursive Type- Economic and Statistical Aspects", Sankhya, 11 (1951), 205-216.

Zellner, A. and F. Palm (1974), "Time Series Analysis and Simultaneous Equation Econometric Models", Journal of Econometrics, 2, 17-54.

\footnotetext{
${ }^{16}$ this has changed from 2005 to 2009
} 


\section{Appendix}

The table is a sub-set of published studies and adopts a taxonomy which distinguishes between cases where only sign restrictions are used (often there are mixtures of sign and parametric restrictions), the type of shock (permanent or transitory), the number of shocks identified, and whether the sign restrictions come from a formal model or not. 
Table 1:

Table 3 Summary of Empirical VAR Studies Employing Sign Restrictions

Fluctuations $\quad$ Ruffer et al (2007) STNI

Peersman (2005) STNI

Sanchez (2007) STNF

Ex Rate Scholl/Uhlig (2005) STNI

Farrant/Peersman (2006) STNF

Bjornland/Halvorsen (2008) MTNI

Lewis (2007) STNF

$\operatorname{An}(2006)$ STOI

Fiscal Policy Mountford/Uhlig (2005) STNI

Dungey/Fry(2008) MPTNI

Housing Jarociński/Smets (2008) MTNI

Vargas-Silva (2008) STOI

Monetary Policy Faust (1998) STOI

Canova/De Nicoló (2002) STOF

Mountford (2005) STNI

Scholl/Uhlig (2005) STNI

Uhlig (2005) STOI

Rafiq/Mallick (2008) STOI

Technology $\quad$ Francis/Owyang/Theodorou (2003) MPTOI

Peersman/Straub (2004) STNF

Francis/Owyang/Roush (2005) MPTOF

Dedola/Neri (2007) SPTOF

Chari/Kehoe/McGrattan (2008) MPTNF

Various Hau and Rey (2004) STNF

Eickmeier/Hoffmann/Worms (2006) STNI

Fujita(2009) STOI

Restriction Type: $\mathrm{S}=$ Sign only, $\mathrm{M}=$ Mixed

Shock Types: $\mathrm{P}=$ Permanent, $\mathrm{T}=$ Transitory

Number of Shocks: $\mathrm{O}=$ One only, $\mathrm{N}=$ Numerous

Restriction Source: F=Formal, I= Informal 